\title{
A Produção do Conhecimento em Cidadania no Brasil: uma análise a partir do Scielo (1992-2011)
}

Augusto Junior Clemente ${ }^{1}$

Maíra Cabral Juliano ${ }^{2}$

Resumo

Este artigo relata resultados de um estudo de caráter bibliométrico sobre a produção do conhecimento brasileira acerca da cidadania presente no Scielo (Scientific Eletronic Library Online). Em um corpus de 203 artigos e extensão temporal de 20 anos (1992-2011) foram analisadas variáveis como: ano da publicação, filiação institucional de autores e periódicos, referências bibliográficas e conteúdo de palavras-chaves e títulos. 0 critério para seleção dos artigos foi o de possuir o termo "cidadania" como uma de suas palavras-chaves. Por um lado, foi constatado o crescimento da cidadania como um campo teórico, com alta concentração institucional e geográfica. Por outro, a hipótese de que os conceitos de cidadania mobilizados no Brasil estão incrementando a abordagem tradicional marshalliana, focada em direitos e senso de pertencimento.

Palavras chave: Cidadania, Produção do conhecimento, Estudo bibliométrico

\footnotetext{
${ }^{1}$ Doutor em Ciência Política. Professor da Universidade Federal do Pampa (UNIPAMPA). Email: augustoclemente@unipampa.edu.br

${ }^{2}$ Bacharel em Psicologia e especialista em Psicologia Clínica, Universidade Tuiuti do Paraná (UTP). Email: maira cabral@yahoo.com.br
} 


\title{
The Production of Knowledge about Citizenship in Brazil: an analysis based on Scielo (1992-2011)
}

\begin{abstract}
This article is the result of a bibliometric study of the Brazilian production of knowledge about citizenship in SciELO (Scientific Electronic Library Online). In a corpus of 203 articles and temporal extension of 20 years (1992-2011) it was analyzed the variables: year of publication, institutional affiliation of authors and periodicals, references and content of titles and keywords. The criterion for selection of the articles was to own the citizenship term as one of your keywords. On one hand, it was observed the growth of citizenship as a theoretical field with high institutional and geographic concentration. In other hand, the assumption that concepts of citizenship mobilized in Brazil have been increasing the traditional Marshallian approach focused on rights and sense of belonging.
\end{abstract}

Keywords: Citizenship, Knowledge production, bibliometric study

\section{Introdução ${ }^{3}$}

Durante o processo de transição de regime político no Brasil, que teve início nos anos 1970 e encerrou na década de $1980^{4}$,

\footnotetext{
${ }^{3}$ Este texto teve diversas contribuições oriundas tanto de submissões em eventos científicos quanto de interlocuções críticas com colegas que, de alguma forma ou de outra, colaboraram com a sua construção. Por isso, fica registrado o agradecimento ao grupo de pesquisa Processos Participativos na Gestão Pública, liderado pelo professor Alfredo Alejandro Gugliano (UFRGS); aos professores João Feres Junior (IESP), Hélio Alves (UFRGS), Davide Carbonai (UNIPAMPA), Fabiano Engelmann (UFRGS), Adriano Codato (UFPR) e Javier Amadeo (UNIFESP); e, por fim, aos amigos de sempre: Rodrigo Mayer, Ícaro Engler, Carlos Gallo, Rodrigo Bordignon e Pompílio Locks.

${ }^{4}$ O Brasil tem uma das mais longas transições políticas, que se inicia no Governo Geisel (1974-1979) e finaliza com a posse do Presidente Sarney em 1985. Todavia, a duração da transição brasileira não é consensual. Por exemplo, há autores que colocam as eleições de 1982 como inicio do processo (MAINWARING\& SHARE, 1986).
} 
e, em especial, após a própria redemocratização, tanto os atores políticos engajados no respectivo processo, quanto a produção acadêmica voltada às questões relacionadas aos fenômenos políticos, procuraram oferecer respostas para as preocupações da consolidação democrática. Dentre tais preocupações encontra-se a temática da cidadania.

Neste sentido, este artigo tem como propósito realizar uma exploração inicial do modo pelo qual se organiza a produção do conhecimento no Brasil, sobre o conceito de cidadania. Foram tomados por objeto de análise os artigos científicos de todas as áreas do conhecimento que percebem a cidadania enquanto uma questão de preocupação $^{5}$. 0 material empírico que compôs o corpus de análise foi coletado a partir da base Scielo (Scientific Eletronic Library Online), que comporta grande parte das revistas especializadas e legitimadas pelo campo acadêmico nacional. A presença no Scielo foi considerada, para os propósitos desta pesquisa, um proxy do impacto potencial de um artigo. Contribuir

O critério para o recorte da pesquisa foi a seleção dos artigos científicos que possuem o termo "cidadania" como uma de suas palavras-chaves, em periódicos editados no Brasil. A opção por este recorte partiu do princípio de que se um texto tem como uma das suas palavras-chaves "cidadania”, então, nele há algum conceito (explícito ou implícito) sobre a referida palavra. Desta forma, o corpus final proporcionou uma extensão temporal de 20 anos - de 1992 até 2011 - e um montante de 203 artigos escritos por 342 autores - contando as publicações colaborativas com mais de um autor (ver Anexo). A opção por esse foco de análise se dá pelo fato de que as revistas científicas constituem

\footnotetext{
${ }^{5} \mathrm{O}$ recorte inicial contemplava somente o campo das Ciências Humanas. Porém, durante o processo de coleta de dados ficou perceptível que havia um leque grande de pesquisadores e de periódicos de outras áreas que se debruçavam sobre a questão da cidadania. Por exemplo: Ciências Farmacêuticas, Medicina, Neuropsiquiatria, Química, Ciências Biológicas, etc. Recortar o objeto para somente as Ciências Humanas, representaria excluir um elemento estruturante da construção do conhecimento sobre cidadania no Brasil.
} 
núcleos privilegiados de produção do conhecimento, e, por conseguinte, da própria forma de interpretação e representação social dos sentidos que a cidadania adquire.

Como ressalta Melo (1999), nas suas atividades cotidianas os pesquisadores trabalham com e produzem textos acadêmicos. Este material é transacionado ao longo dos circuitos do ensino e da pesquisa, gerando representações da sociedade. É por isso que uma investigação centrada em tais textos pode dizer algo a respeito da forma pela qual as interpretações e representações sociais acerca da cidadania são construídas. Por esta perspectiva, esta pesquisa oferece uma via de acesso àquilo que os pesquisadores compreendem sobre o conceito de cidadania, que faz com que seu repertório intelectual seja, em alguma medida, compartilhado por outras pessoas.

QUADRO 1 - Categorias de Análise da Produção sobre Cidadania

\begin{tabular}{|l|l|}
\hline CATEGORIAS & SIGNIFICADO \\
\hline Ano & Ano de publicação do trabalho. \\
\hline Publicação & $\begin{array}{l}\text { Nome da revista especializada na qual o artigo foi publi- } \\
\text { cado. }\end{array}$ \\
\hline Instituição do autor & $\begin{array}{l}\text { Filiação institucional do(s) autor(es) do artigo. Pode ha- } \\
\text { ver mais de um autor. }\end{array}$ \\
\hline Instituição da publicação & Instituição que sedia a publicação. \\
\hline Estado da publicação & Estado da instituição que sedia a publicação. \\
\hline Região da publicação & Região do país que sedia a publicação. \\
\hline $\begin{array}{l}\text { Estado/país da instituição } \\
\text { do autor }\end{array}$ & $\begin{array}{l}\text { Estado ou país da filiação institucional do(s) autor(es). No } \\
\text { caso de múltipla autoria, a filiação também pode ser múl- } \\
\text { tipla. }\end{array}$ \\
\hline $\begin{array}{l}\text { Região/país da instituição } \\
\text { do autor }\end{array}$ & Região do país ou país a que pertencem os autores. \\
\hline Gênero & Gênero - masculino ou feminino - do(s) autor(es). \\
\hline Área da publicação & Campo do conhecimento no qual a publicação se insere. \\
\hline Área do autor & $\begin{array}{l}\text { Campo do conhecimento no qual o(s) autor(es) se } \\
\text { insere(m). }\end{array}$ \\
\hline Palavras-chave & Palavras-chaves cocitadas com o termo "cidadania". \\
\hline Títulos & Palavras dos títulos dos artigos, excluindo "cidadania". \\
\hline Referências-chaves & Autores que compõem as listas bibliográficas. \\
\hline
\end{tabular}




\begin{tabular}{|l|l|}
\hline $\begin{array}{l}\text { Redes: medidas de } \\
\text { centralidade }\end{array}$ & $\begin{array}{l}\text { Análises de rede das listas bibliográficas por medidas de } \\
\text { centralidade entre as referências-chaves. }\end{array}$ \\
\hline Redes: cliques & $\begin{array}{l}\text { Análises de rede das listas bibliográficas para identificar } \\
\text { os subgrupos de referências-chaves }\end{array}$ \\
\hline Fonte: elaboração própria
\end{tabular}

Neste sentido, a pergunta que norteia esta pesquisa pode ser escrita da seguinte forma: quais as principais características da produção do conhecimento sobre cidadania no Brasil? Para tentar responder esta questão o estudo mobilizou um conjunto de variáveis dispostas no quadro 1.

Importante frisar que neste trabalho será evitada propositalmente a discussão teórica sobre cidadania no Brasil - há inúmeros trabalhos que a fazem (TAVORALO, 2008; 2009; SOUZA, 2006; SANTOS, 1987; SAES, 2001; PINSKY \& PINSKY, 2003; CARVALHO, 2001) - para focar em algumas características da produção bibliográfica do conceito em tela. Somente uma exposição mínima sobre as teorias da cidadania será exposta nas linhas que seguem.

É no período pós Segunda Guerra Mundial, no contexto da segunda onda democrática (HUNTINGTON, 1994) e, também, do avanço da social democracia em alguns países da Europa - tal como, a Grã Bretanha - que a cidadania ganhou maior repercussão enquanto teoria propriamente dita, pela obra de Thomas Humphrey Marshall (1949). 0 autor destaca que durante os processos de modernização três esferas de direitos se formalizaram devido a normas que se autonomizaram. Segundo o autor:

O elemento civil é composto por direitos necessários à liberdade individual - liberdade da pessoa, liberdade de fala, de pensamento e fé, o direito de propriedade e de concluir contratos válidos, e o direito à justiça.[...] as instituições mais diretamente associadas aos direitos civis são as cortes de justiça. Por direitos políticos eu entendo o direito de participar no exercício do poder político, como um membro de 
um corpo investido de autoridade política ou como eleitor de membros de tal corpo. As instituições correspondentes são o parlamento e os conselhos locais de governo. Quanto ao elemento social entendo ser toda uma gama de direitos, desde um modicum de segurança e bem-estar econômico até o direito de compartilhar por completo a herança social e de viver a vida de um ser civilizado conforme os padrões prevalecentes na sociedade. As instituições mais conectadas a ele são o sistema educacional e os serviços sociais (MARSHALL, 1949, p.08)

Marshall sustenta que estes conjuntos de direitos se institucionalizaram em momentos históricos distintos em função de pressões vindas de atores políticos diferentes: os direitos civis se afirmaram no decorrer do século XVIII, os direitos políticos no século XIX e os direitos sociais no século XX.

Como recorda Tavoralo (2008; 2009), a teoria de Marshall foi alvo de muitas objeções. Aqui, serão citadas apenas duas, e sucintamente: Tom Bottomore (1992) alertou que a ordem (crono) lógica de Marshall não explica experiências nas quais direitos sociais foram conquistados antes dos outros conjuntos de direitos. No mesmo sentido, Margaret Somers (1993) argumenta que as classes do modelo marshalliano agregaram indivíduos de origens socioeconômicas distintas com interesses por vezes divergentes, e com projetos políticos que não necessariamente possuíam identidades classistas.

O que é preciso reter desta explanação inicial é que os conceitos políticos fundamentais formam campos de conhecimento marcados por disputas teóricas. Os autores textuais também podem ser encarados como tipos específicos de atores políticos envolvidos em confrontos retóricos. Assim, ao conceituarem algo sempre haverá um potencial de prognóstico que cria novos horizontes de expectativas. Nas palavras de Koselleck (2006): não se trata mais, portanto, de conceitos que classificam experiências, mas sim de conceitos que criam experiências (p. 324). 
0 artigo está dividido da seguinte forma: em primeiro lugar será apresentada uma "radiografia" inicial da produção científica brasileira que se debruça sobre a temática da cidadania, com foco nos atributos dos artigos. Em seguida, será realizada uma análise centrada no conteúdo dos mesmos, com vistas a algumas interpretações conceituais. Por fim, serão desenhadas as considerações finais. Com este trabalho, que é a primeira publicação de um projeto de maior fôlego, se pretende contribuir para expandir o conhecimento que atualmente existe sobre os debates envolvendo cidadania - e porque não também da democracia no contexto brasileiro e suas diferentes inter-relações.

\section{Atributos dos artigos}

Para entender a evolução da produção acadêmica brasileira sobre cidadania é interessante começar por contextualizar os trabalhos numa linha temporal, como mostra o Gráfico 1.0 primeiro artigo disponibilizado eletronicamente no Scielo - que tem "cidadania" como palavra-chave - data de $1992^{6}$. De todo modo, há uma linha ascendente desde 1992 até 2011, mas que atinge um pico no ano de 2008, com 25 trabalhos publicados, equivalendo a $12,3 \%$ de toda a longitude. A responsabilidade por esse pico fica a cargo dos estudos da área da saúde, com 8 revistas que abrigaram artigos. Não há uniformidade na produção, porém, uma tendência de linha ascendente com uma agenda robusta de pesquisas sobre cidadania a partir do ano de 2000.

\footnotetext{
${ }^{6}$ Não há porque pensar que antes não se publicava a respeito da cidadania. A questão é que o Scielo enquanto sistema de acesso aberto à pesquisa começa a funcionar efetivamente em 1997. Por isso, acredita-se que as informações estejam defasadas, explicando o porquê do período pré-1997 ter poucos artigos.
} 


\section{Gráfico 1 - Publicações por ano}

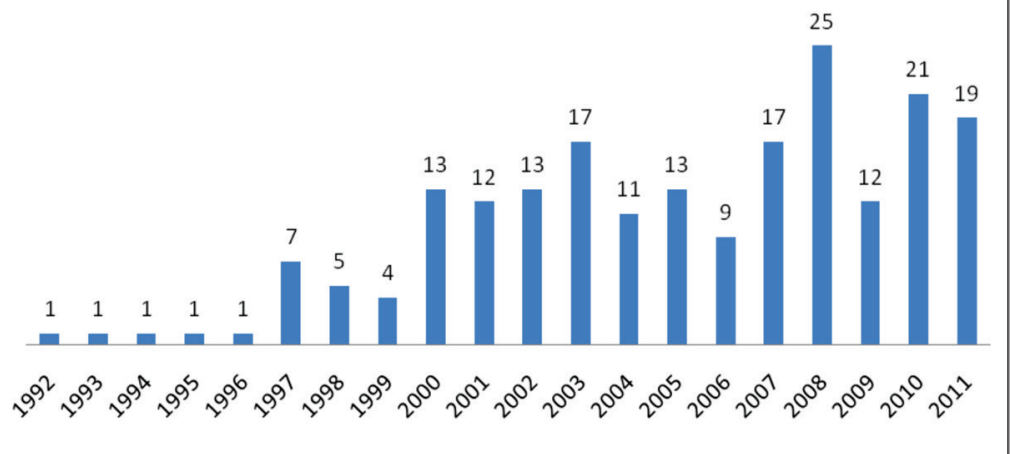

Fonte: elaboração própria a partir do Portal Scielo

0 Gráfico 2 aponta para os periódicos que mais abrigaram artigos que versam sobre a temática aqui analisada. Entre eles destacam-se as revistas Ciência \& Saúde Coletiva (11 casos), Sociedade e Estado (9 casos), Ciência da Informação (8 casos), Educação \& Sociedade (8 casos), Cadernos de Pesquisa (7 casos), Revista Brasileira de Ciências Sociais (7 casos), Revista Brasileira de Educação (6 casos), e São Paulo em Perspectiva (6 casos). Não é possível afirmar que há concentração dos periódicos que receberam os artigos analisados. Eles estão dispersos em mais de 50 revistas diferentes. Esses números mostram que há uma boa quantidade de periódicos, de impacto acadêmico entre médio e alto, dispostos a publicar material relacionado à cidadania no Brasil. 


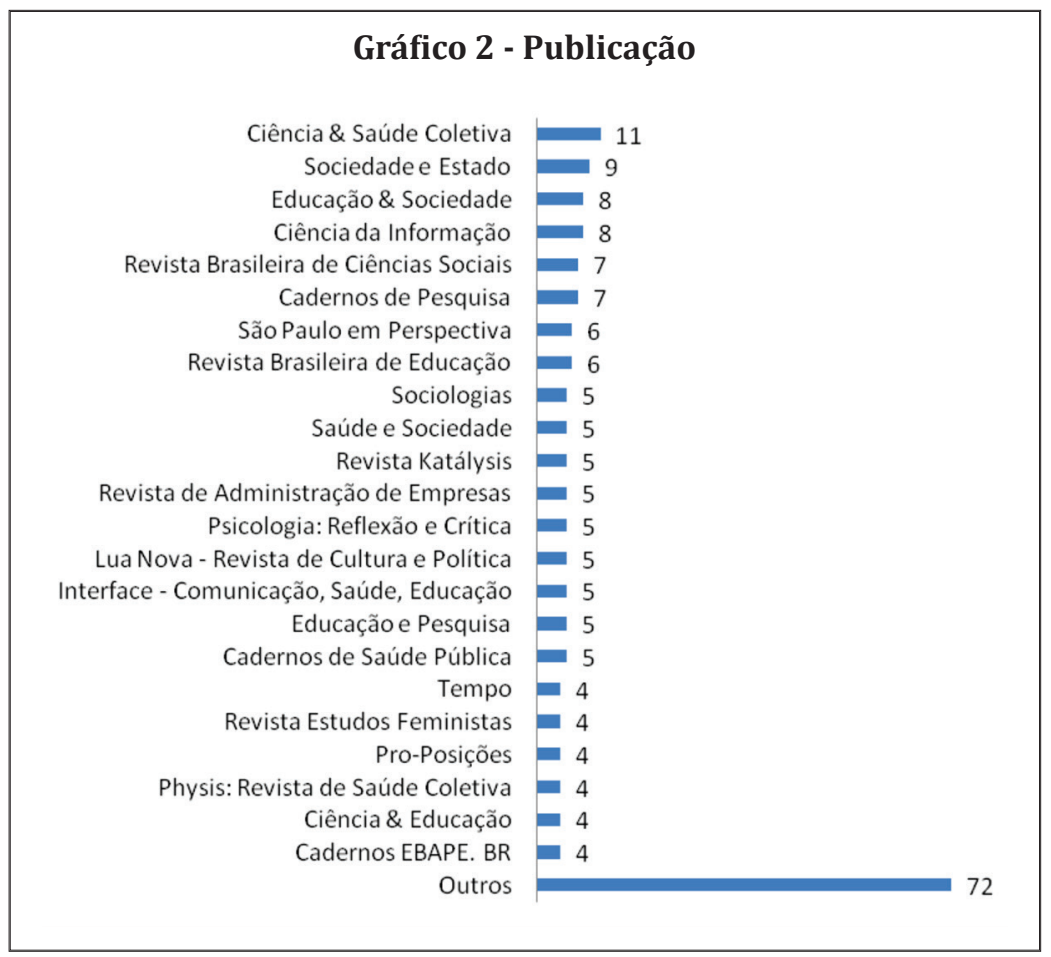

Fonte: elaboração própria a partir do Portal Scielo

Estas revistas científicas estão abrigadas pelas instituições demonstradas pelo Gráfico 3. Quando se analisa esse gráfico, percebe-se que há grande leque de instituições que acomodam os periódicos, porém com relativa concentração institucional: a UNICAMP abriga 20 Revistas, a FIOCRUZ abriga 19, a USP tem 18 periódicos e a UNESP e UFRGS abrigam 12 cada. 


\section{Gráfico 3 - Instituição da Publicação}

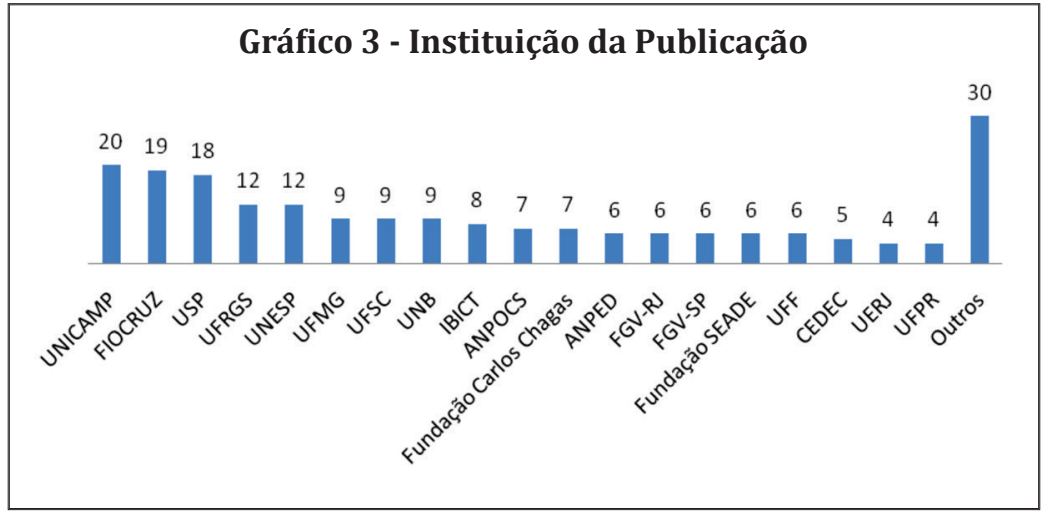

Fonte: elaboração própria a partir do Portal Scielo

Em relação ao gênero dos autores, apura-se o predomínio das mulheres (Gráfico 4). De um total de 342 autores, 201 são do gênero feminino (quase 60\%). Esse é um dado interessante quando se considera a contribuição feminista ao debate da cidadania. Não obstante, há um número relativamente baixo de trabalhos sobre o tema específico de gênero (13 casos), isto é, sobre exclusão da mulher da alçada da cidadania moderna.

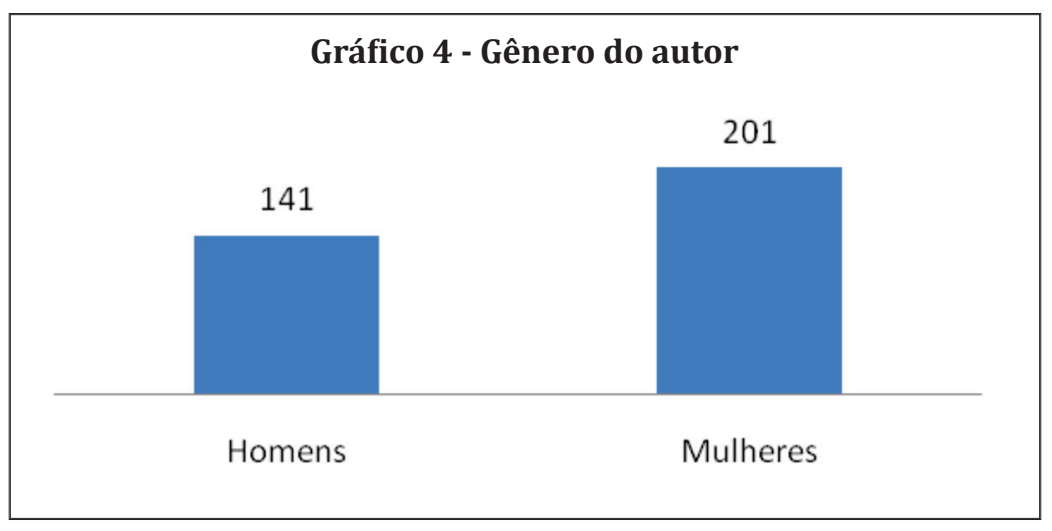

Fonte: elaboração própria a partir do Portal Scielo 
No tocante à autoria, verifica-se uma "dispersão concentrada" (Gráfico 5). Ou seja, dos 342 autores que publicaram trabalhos relacionados à temática em questão, 29 são da USP, 20 da UNB, 19 da UNICAMP e 18 da UFSCAR e da UFRJ. Estes resultados refletem o acúmulo quantitativo e qualitativo destas instituições em pesquisas no tema. Outras instituições também tentam figurar entre estas, como é o caso da FIOCRUZ, UERJ, UFSC e UFV.

Como fica implícito nos dados anteriores, há uma concentração geográfica da produção científica quando se consideram os estados e regiões da produção. 0 Gráfico 6 mostra essa concentração, levando em conta os estados das revistas acadêmicas. Dois estados (São Paulo e Rio de Janeiro) concentram 67,5\% das publicações, quase dois terços, seguidos pelo Distrito Federal e Rio Grande do Sul.

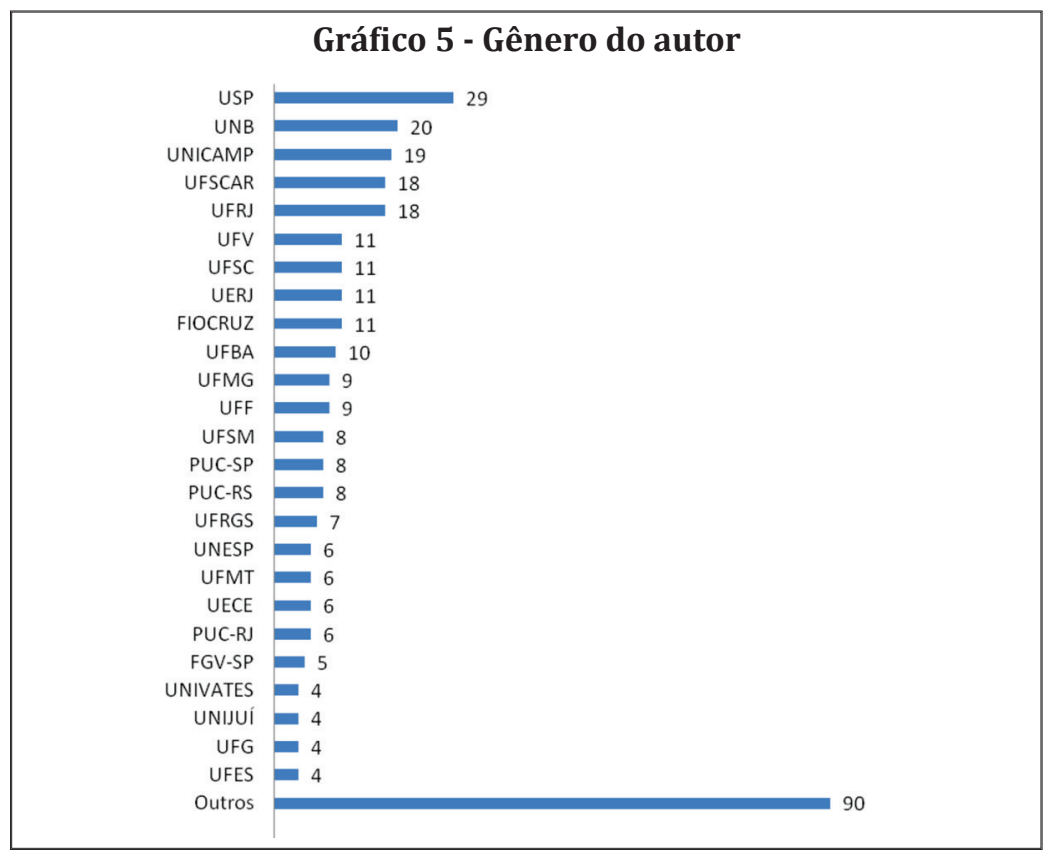

Fonte: elaboração própria a partir do Portal Scielo 
Ao agregar os resultados para as regiões brasileiras, a concentração geográfica se torna ainda mais evidente (Gráfico 7). Mais de $70 \%$ dos artigos aparece na região sudeste. 0 sul também sedia um número considerável (33 casos), bem como a região centro-oeste. Estas três regiões, portanto, concentram praticamente a totalidade das instituições que publicam algo sobre a temática em apreço. 0 nordeste aparece somente com quatro casos.

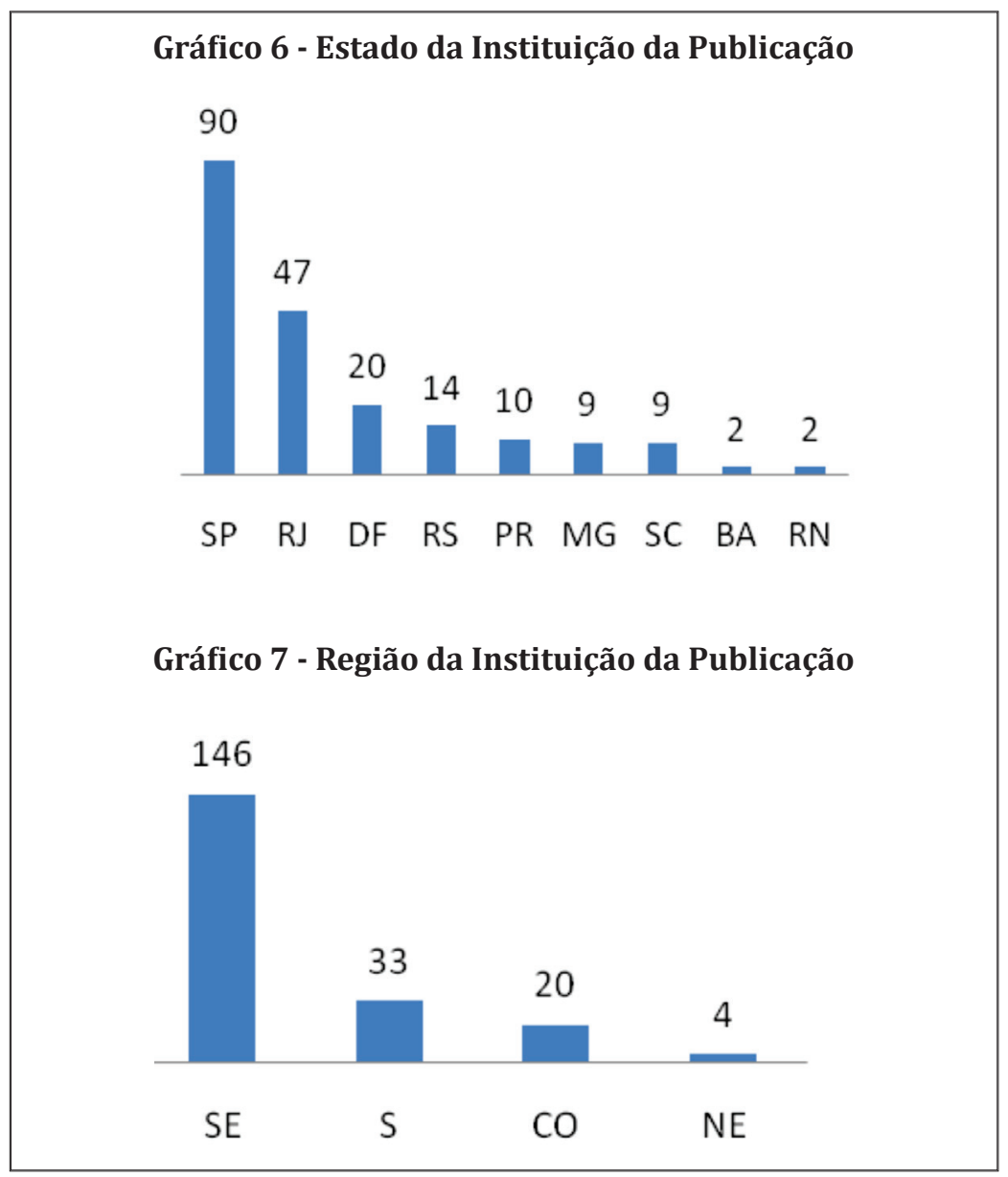

Fonte: elaboração própria a partir do Portal Scielo 
A concentração geográfica também é visível quando se considera o estado/país da filiação institucional dos autores. A situação se repete, mas inclui entre os autores que mais publicaram aqueles pertencentes aos estados do Rio Grande do Sul, Minas Gerais e o Distrito Federal (Gráfico 8). Chega a ser curioso que pesquisadores oriundos do país de Portugal (7 casos) publicam mais sobre cidadania Brasil nos periódicos indexados ao Scielo do que muitos estados brasileiros, sendo que o mesmo vale para pesquisadores norte-americanos (4 casos).

Ao se agregar os resultados pela região a que pertence o autor, o sudeste concentra cerca de $60 \%$ da produção com 199 casos (Gráfico 9). 0 sul apresenta 56 casos, o centro-oeste aparece com 36 e o nordeste com 28. Brasilianistas compõem 21 casos e o norte - em vinte anos de produção - teve apenas 2 pesquisadores.

É válido destacar que num país com proporções continentais como o Brasil, onde severas desigualdades sociais dos mais diversos tipos afetam a consolidação da cidadania, a concentração da produção acadêmica em poucas regiões e instituições torna-se injustificável. Contudo, pode-se supor que estudos sobre cidadania de outras regiões que não as do sudeste, sul e centro-oeste, não acedam às publicações do Scielo por vários outros motivos. Pode-se, por exemplo, inferir que há um controle da agenda de pesquisa em algumas instituições, que direcionam a produção em um sentido diferente daquele dado a pesquisadores locais. 


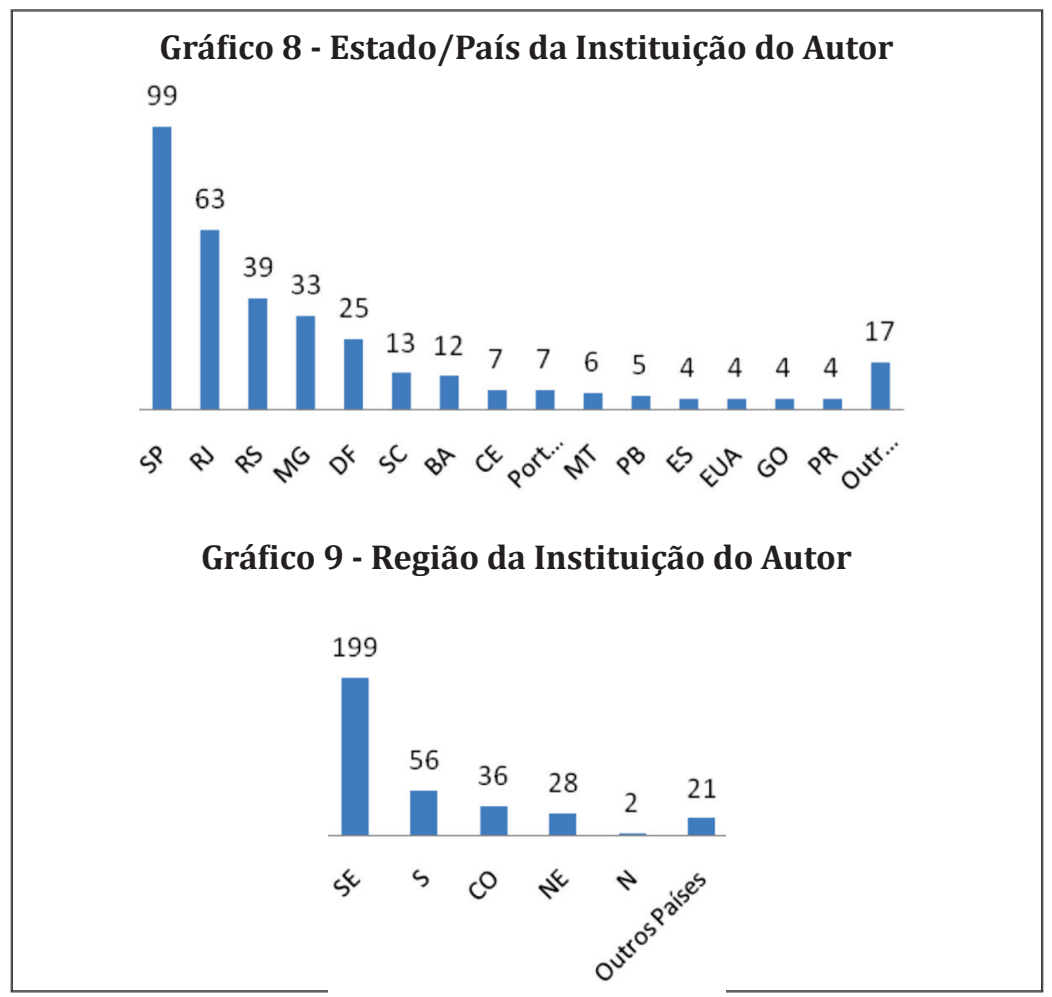

Fonte: elaboração própria a partir do Portal Scielo

Para compor as informações sobre as áreas do conhecimento em que se concentram as revistas foram observadas as informações fornecidas pelas mesmas. E no caso dos autores foi considerada a última área de concentração dos seus títulos, informada pelo currículo lattes de cada qual. Foram agregadas algumas áreas numa única área, como, por exemplo, Saúde - que inclui enfermagem, psiquiatria, psicologia, saúde coletiva, neurologia, medicina, etc. - e Ciências Sociais - que inclui ciência política, sociologia, relações internacionais e antropologia.

O Gráfico 10 aponta para aglutinação por área do conhecimento das revistas científicas. A surpresa é que a área do conhecimento das re- 
vistas que mais recebem artigos sobre cidadania é a Saúde, com 49 casos. As revistas de Ciências Sociais e Educação somam 45 casos cada. As três áreas do conhecimento juntas representam quase dois terços dos periódicos interessados no debate a respeito da cidadania. Espanta, contudo, a quase ausência de periódicos da área Jurídica, com apenas 1 caso, uma vez que uma noção mínima de cidadania é justamente aquela que reza sobre a conquista e a fruição dos direitos.

Importante notar que publicações de diversas outras áreas também recebem artigos sobre cidadania, constituindo temática de revistas devotadas a campos os mais diversos, com destaque para a Administração (púbica e privada) e Ciências da Informação. Há, assim, uma variedade de aplicações do conceito de cidadania que revela seu caráter multidisciplinar.

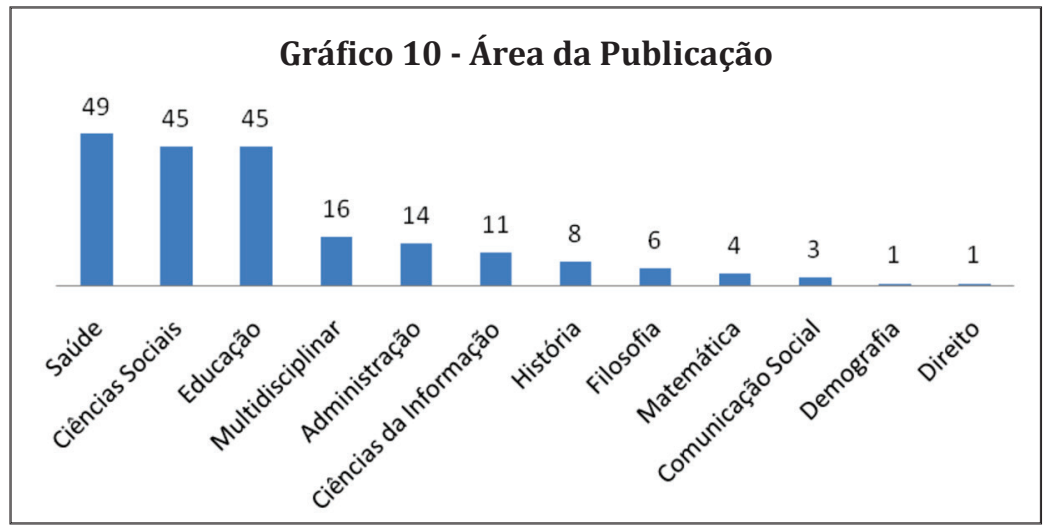

Fonte: elaboração própria a partir do Portal Scielo

No que concerne à área de concentração dos autores dos artigos (Gráfico 11), a dinâmica é semelhante. Como no caso das publicações, predomina a área da Saúde com 112 casos (só a psicologia tem 37 casos), as Ciências Sociais somam 73 casos (isolada, a Sociologia tem 40 casos) e a Educação com 53 casos. Entretanto, há espaço no debate para as áreas das Ciências da Informação/Comunicação, Administração e História. Mas novamente, percebe-se uma profusão de campos de conhecimento. 
Encerra-se aqui a exploração de alguns dos atributos dos artigos. Cabe agora apresentar algumas das características conceituais que permeiam o debate do objeto em apreço.

\section{Conteúdo dos artigos}

Com o intuito de perceber algumas das possíveis associações conceituais da cidadania, construídas pelo léxico acadêmico, foi identificado o padrão de cocitação das palavras-chaves dos artigos junto ao termo "cidadania". 0 montante de palavras-chaves coletadas (excluindo "cidadania", presente em todos os artigos) foi de 750 termos. A nuvem de palavras abaixo (figura 1) ilustra os termos mais usados ${ }^{7}$. 0 que se buscou com essa ferramenta foi perceber algumas "pistas" da produção conceitual, encontrando as associações mais freqüentes ao conceito. Mais do que isso, esta técnica permite um olhar sobre quais direcionamentos teóricos e empíricos os autores dos artigos aqui analisados têm tomado. Ou seja, permite-se vislumbrar os rumos da produção do conhecimento em cidadania no Brasil.

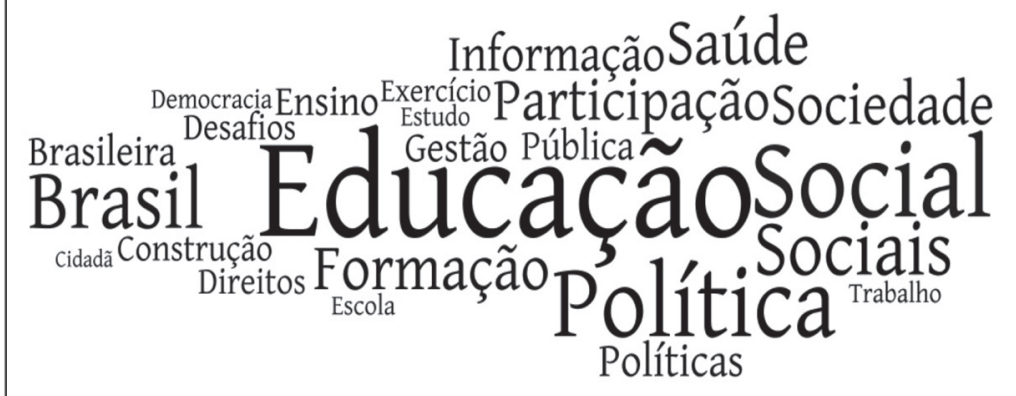

Imagem 1: Frequência das palavras-chaves cocitadas com "cidadania".

Fonte: elaboração própria a partir do Portal Scielo

${ }^{7}$ As nuvens de palavras-chaves foram construídas com a utilização do software livre de análise de conteúdo Many Eyes. 
Foi adotado o mesmo procedimento pala verificar a frequência dos termos que mais apareceram nos títulos dos artigos (Imagem 2) e a nuvem de palavras resultante foi muito parecida com a primeira.



Imagem 2: Frequência das Palavras dos Títulos dos Artigos

Fonte: elaboração própria a partir do Portal Scielo

A observação das duas nuvens permite algumas inferências: a proeminência de "educação" enquanto termo mais associado à cidadania aponta para um dos problemas mais graves da sociedade brasileira, sendo objetos e temas de estudo de grande parte dos artigos. Tal termo, ainda, dá um direcionamento conceitual vinculado à ideia de que a cidadania inexiste sem uma fase formativa. Contudo, a presença de palavras como "participação", "política”, "democracia", também aponta para uma compreensão sobre a capacidade pedagógica da participação democrática. Outras palavras como "informação", "gestão", "social”, "saúde” revelam os objetos e temas de investigação mais frequentes no corpus aqui analisado, bem como para as áreas de concentração dos pesquisadores: Saúde, Ciências da Informação, Ciências Sociais, Administração, etc.

Outra forma de saber quais os caminhos que a produção acadêmica sobre cidadania tem trilhado refere-se às teorias que servem de lente interpretativa aos fenômenos analisados pelos 
autores dos artigos aqui observados. 0 Gráfico 12 apresenta as referências-chaves, ou seja, os teóricos mais citados nas listas de referências bibliográficas dos artigos. As 24 referências-chaves, citadas por um mínimo de dez artigos, formam parte considerável das fontes que subsidiam o léxico da produção científica brasileira voltada para a cidadania.

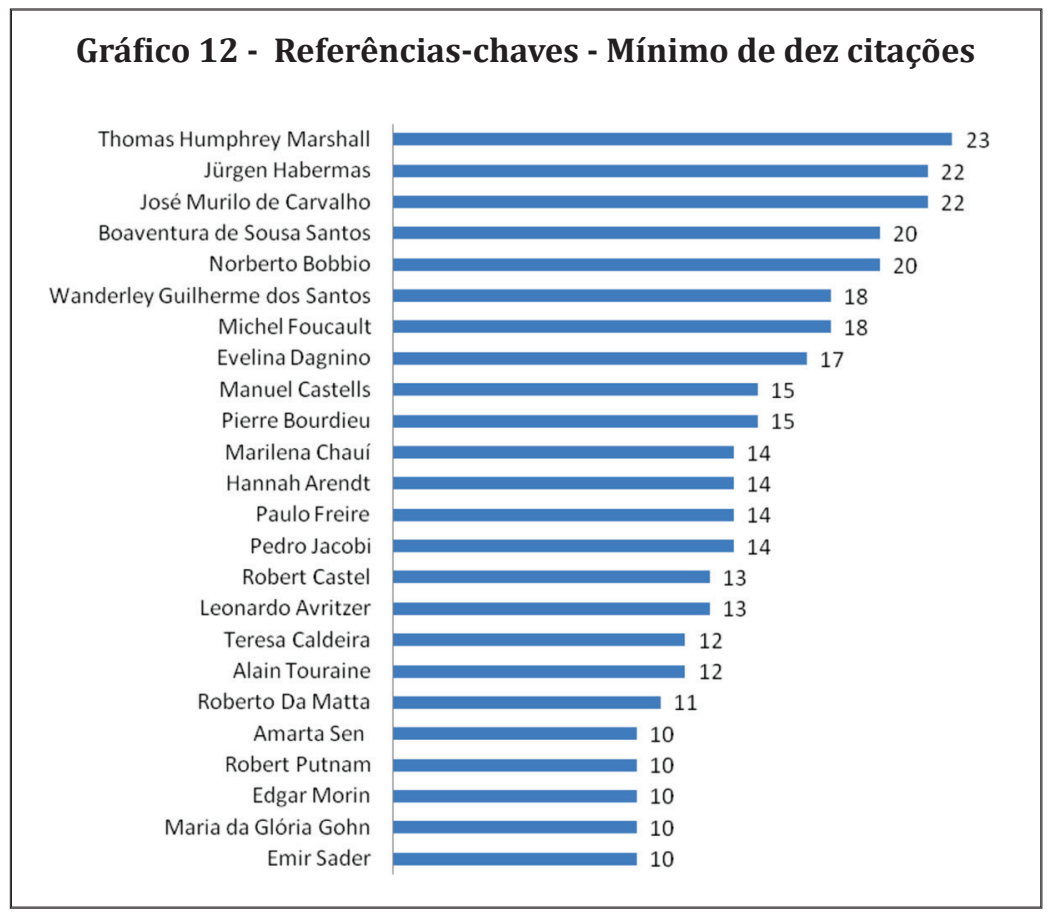

Fonte: elaboração própria a partir do Portal Scielo

Um ponto a se ressaltar é que mesmo com um caráter multidisciplinar, e com grande aglomeração nas áreas da Saúde e Educação, a temática da cidadania é composta por um léxico teórico dado prioritariamente pelas Ciências Sociais. Uma hipótese que pode explicar esse predomínio é a tese de Manuel Palacios da Cunha e Melo (1999), de que as interpretações do Brasil - pensamento político e formação social - foram dadas por autores 
vinculados às Ciências Sociais. Esta área do conhecimento seria a resposta para a pergunta que Melo se faz, e que dá o nome à sua obra - Quem explica o Brasil.

Alguns nomes já eram esperados enquanto autores de impacto nas listas das referências bibliográficas, como é o caso de Marshall, Bobbio, Carvalho, Dagnino, entre outros. Todavia, outros nomes foram uma surpresa, pelo fato de não teorizarem especificamente sobre o conceito em apreço, mas sobre outras temáticas que podem ou não se vincular aos conceitos de cidadania, como é o caso de Habermas, Sen, Foucault, Castells, Bourdieu, Freire, etc. A explicação para este achado pode ser aquela apresentada pela história dos conceitos no que se refere ao estudo da recepção conceitual: os leitores interpretam criativamente as teorias de que se apropriam (RICHTER, 2006). Ou seja, por mais que Foucault e Bourdieu, não tenham escritos específicos sobre cidadania, seus interlocutores (os pesquisadores) "encontram" alguma concepção de cidadania subjacente em seus textos.

No entanto, mais relevante que conhecer as referências-chaves é saber qual é o padrão estrutural do campo em apreço. Para tanto, foram utilizados alguns instrumentos fornecidos pelo estudo de redes sociais ${ }^{8}$. Com isso, foi construída uma matriz com as 24 referências-chaves, na qual cada referência-chave representa um nó e as arestas representam os artigos nos quais duas ou mais referências-chaves eram cocitadas. Ou seja, os vínculos entre as referências-chaves (nós) são os artigos científicos (arestas).

Construída a matriz, a rede que se formou apresentou um alto nível de densidade ${ }^{9}$ : 0,76. Quase todas as referências-chaves se relacionam entre si, fato que demonstra certo nível de amadurecimento teórico do campo. Entretanto, para compreender me-

\footnotetext{
${ }^{8}$ Para realizar a análise de redes foi utilizado o software UCINET 6.

${ }^{9}$ A densidade é o cálculo que mede o total de relacionamentos de uma rede, no qual o máximo possível de relações é representado por 1 e a ausência de relações é 0 .
} 
lhor as suas subdivisões internas e posições estratégicas, dois outros conjuntos de ferramentas do estudo de redes sociais foram utilizados: medidas de centralidade e cliques.

Começando pela primeira, a tabela 2 traz os valores referentes às centralidades de grau e de intermediação. A primeira demonstra as relações diretas entre os nós, medida pela quantidade de arestas que um nó possui com os demais nós da rede. A centralidade de intermediação, por sua vez, aponta para qual nó possui posição estratégica, por controlar os fluxos de informações, integrando os subgrupos. Em outras palavras, ela aponta para qual nó funciona como uma espécie de relé de um sistema elétrico que intensifica sua densidade.

Tabela 2 - Centralidades das Referências-Chaves

\begin{tabular}{|l|c|c|c|}
\hline \multicolumn{1}{|c|}{ Referências } & Grau & Grau de entrada & Intermediação \\
\hline SANTOS, B. S. & 23 & 68 & 6,889 \\
\hline BOBBIO, N. & 18 & 41 & 4,767 \\
\hline FOUCAULT, M. & 19 & 30 & 4,520 \\
\hline DAGNINO, E. & 21 & 65 & 3,814 \\
\hline DA MATTA, R. & 18 & 45 & 3,729 \\
\hline JACOBI, P. & 18 & 41 & 3,539 \\
\hline BOURDIEU, P. & 17 & 27 & 3,383 \\
\hline GOHN, M. G. & 19 & 45 & 3,128 \\
\hline HABERMAS, J. & 21 & 70 & 3,087 \\
\hline MARSHALL, T. H. & 21 & 77 & 3,087 \\
\hline SANTOS, W. G. & 21 & 70 & 3,087 \\
\hline CASTELLS, M. & 20 & 36 & 2,688 \\
\hline SEN, A. & 17 & 21 & 2,125 \\
\hline CARVALHO, J. M. & 18 & 63 & 2,101 \\
\hline CALDEIRA, T. & 16 & 42 & 2,019 \\
\hline SADER, E. & 17 & 26 & 2,009 \\
\hline AVRITZER, L. & 19 & 53 & 1,988 \\
\hline FREIRE, P. & 12 & 17 & 1,901 \\
\hline CHAUÍ, M. & 17 & 35 & 1,849 \\
\hline TOURAINE, A. & 18 & 32 & 1,793 \\
\hline CASTEL, R. & 15 & 25 & 1,332 \\
\hline ARENDT, H. & 16 & 33 & 1,208 \\
\hline MORIN, E. & 8 & 9 & 0,682 \\
\hline PUTNAM, R. & 13 & 29 & 0,277 \\
\hline
\end{tabular}

Fonte: elaboração própria a partir do Portal Scielo 
Como referido acima, a rede é bastante densa e é por isso que ao observar os graus de entrada se verifica um número bastante elevado para determinadas referências-chaves: Marshall (77), Habermas (70). Wanderley Guilherme dos Santos (70), Boaventura de Sousa Santos (68) e Carvalho (63). Entre estes, Carvalho, Wanderley Guilherme dos Santos e Marshall são teóricos da cidadania, assim, faz sentido seus elevados graus de centralidade. Habermas, por sua vez, não apresenta um conceito bem delineado do que é cidadania. No entanto, sua concepção de democracia deliberativa possui elevada inserção no Brasil. 0 mesmo ocorre com o sociólogo Boaventura de Sousa Santos, porém, ao contrário dos demais este apresenta um aporte distinto, mais focado em epistemologias pós-moderna e pós-colonial.

Ao dicotomizar a rede tornando-a binária, pode-se visualizar melhor as relações que as referências apresentam entre si, em termos de quantidade de relações existentes dentro da própria rede. É isto que a primeira coluna (Grau) da tabela 2 revela, destacando, por exemplo, Boaventura de Sousa Santos (23) como único autor cocitado com todas as outras referências-chaves. Neste ponto, Marshall (21), Habermas (21), Dagnino (21) e Castells (20) também apresentam medidas de centralidade elevadas. $\mathrm{O}$ fato de referências com distintas abordagens serem com freqüência referenciadas juntas pode sugerir que os redatores dos artigos analisados realizam um debate crítico acerca do conceito de cidadania. Ou seja, o recorte originalmente marshalliano - focado em direitos e senso de pertencimento - parece ser expandido, complementado.

No que tange à centralidade de intermediação, novamente, Boaventura de Sousa Santos $(6,889)$ aparece com destaque, corroborando com as análises anteriores. Outras duas referências-chaves merecem destaque: Bobbio $(4,767)$ e Foucault $(4,520)$. Tais achados revelam que são estas três referências que mais interconectam os subgrupos da rede, ocupando posições estratégicas no fluxo teórico. 0 fato de Bobbio apresentar uma cen- 
tralidade de intermediação elevada pode ser explicado porque este autor escreveu inúmeras obras de teoria política que servem como base e ponto de partida para qualquer estudante que queira se aproximar de conceitos políticos. E ao se recordar que diversas áreas de concentração se debruçam sobre a temática da cidadania, sobretudo Educação e Saúde, parece fazer sentido que um autor generalista como Bobbio seja bastante citado.

Mesmo sem ter condições de realizar afirmações taxativas, a interpretação retirada destes números parece sustentar o argumento de que o conceito de cidadania no Brasil tem trilhado um caminho complementar e de expansão à abordagem marshalliana. E, ao que parece, as pontes usadas para tais complementos são nomes como os de Boaventura de Sousa Santos, Foucault, Castells e, em certa medida, Habermas.

Para além da identificação dos nós fundamentais de uma rede, importa conhecer os seus subgrupos e o seu nível de coesão. A coesão da rede, por meio do estudo das cliques, pode ser representada através de diagramas (imagem 3). 0 diagrama permite visualizar sua "coluna vertebral": quanto mais subgrupos houver menos ramificações existirão no diagrama representativo da rede. Esta técnica aponta para subgrupos de referências-chaves que são formados por padrões de cocitações, isto é, referências que mais vezes aparecem juntas nas listas bibliográficas, que, portanto, formam grupos mais ou menos coesos.

Na imagem 3 verifica-se que a "coluna vertebral" do corpus de análise é formada por três subgrupos coesos - (i) Marshall, Habermas, Wanderley Guilherme dos Santos e Boaventura de Sousa Santos; e as díades (ii) Bourdieu e Foucault, e; (iii) Sen e Sader - nos quais as demais referências se unem às suas linhas, com maior ou menor proximidade - Dagnino, Avritzer, Gonh, Torraine e Castells se unem ao subgrupo (i); Da Matta, Caldeira e Carvalho ao subgrupo (ii); Bobbio e Chauí ao subgrupo (iii). Há ainda outros autores que apresentam proximidades - (v) Arendt 
e Jacobi - ou similaridades, porém, não pela coesão, mas por estarem conectados à rede tangencialmente - (iv) Morin, Putnam, Castel e Freire.

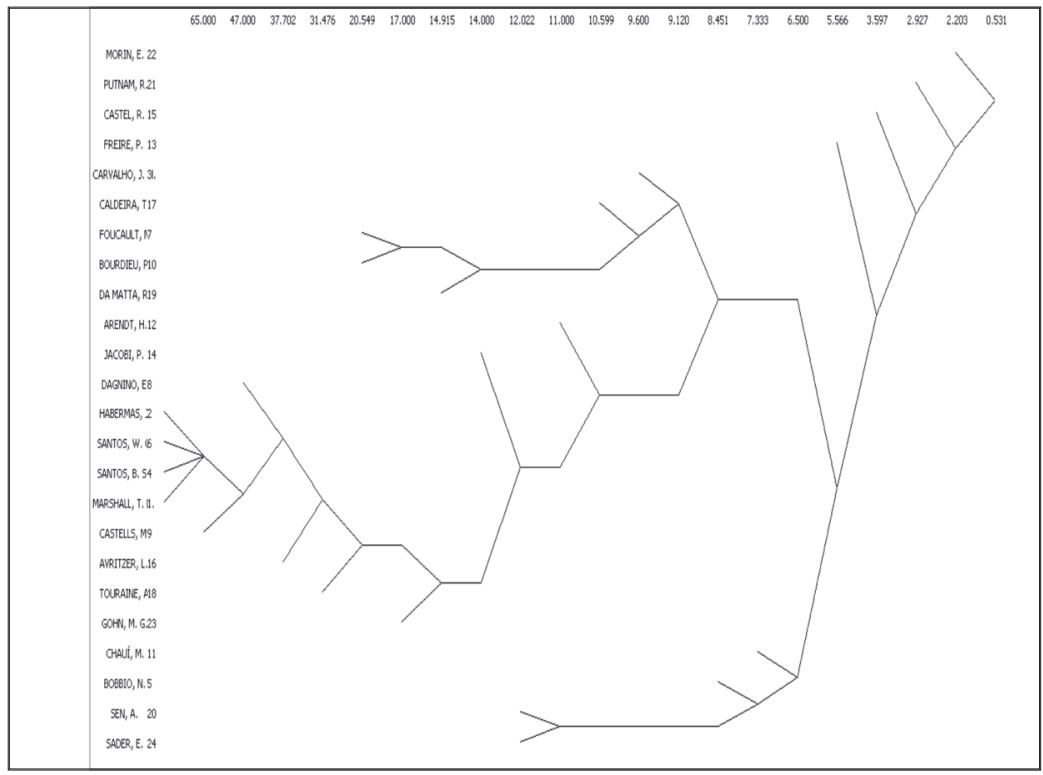

Imagem 3 - Cliques das Referências-Chaves

Fonte: elaboração própria a partir do Portal Scielo

0 diagrama da imagem 3 revela que basicamente a rede se divide em três subgrupos mais bem delineados. 0 subgrupo (i) é o seu núcleo duro, com os autores mais referenciados, comportando tanto perspectivas ortodoxas da cidadania quanto aquelas centradas em abordagens participativas, deliberativas ou em engajamentos em organizações associativas. Nomes como Dagnino, Avritzer, Gohn e Sader comprovam tal afirmação. A interpretação sobre outros nomes vinculados a esta linha, como Castells e, sobretudo, Boaventura de Sousa Santos é a de que eles sugerem a interface com outros subgrupos e referências-chaves. O subgrupo (ii) mostra um agregado de referências relacionadas por aportes teóricos (sociologia francesa) e metodológicos (et- 
nografia) específicos. E o subgrupo (iii), por sua vez, parece se encaixar naquela interpretação anteriormente direcionada ao Bobbio, isto é, de que tal agregado é formado mais estritamente por referências de teoria e filosofia políticas, que oferecem alguma base teórica para aqueles que se aproximam dos conceitos políticos fundamentais, como é o caso da cidadania.

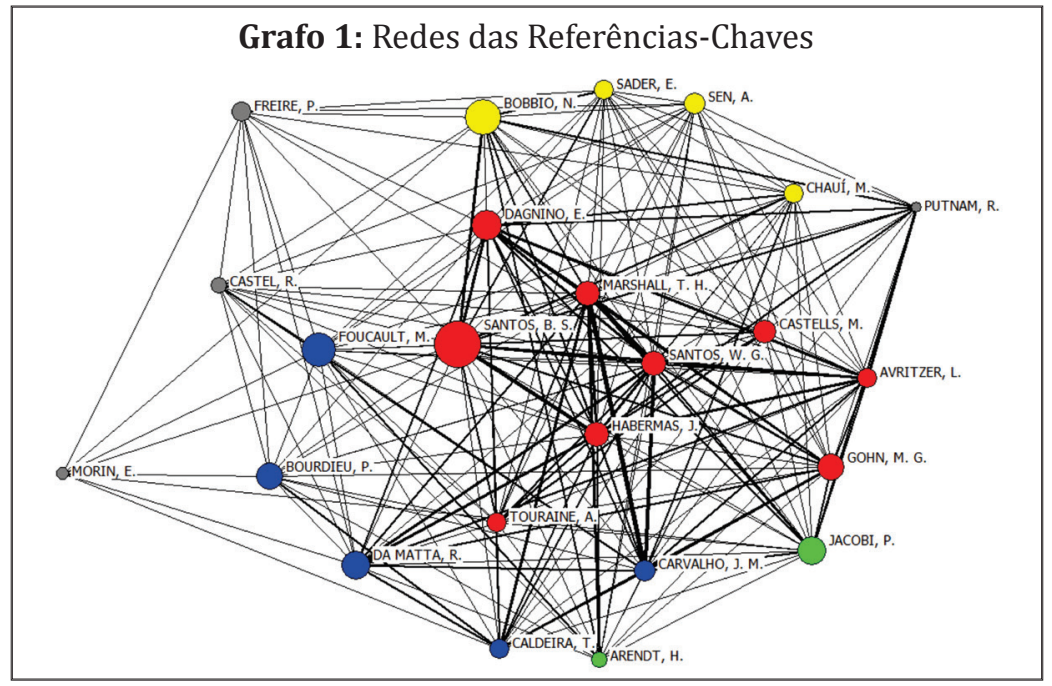

Fonte: elaboração própria a partir do Portal Scielo

Importante ressaltar que as cliques não apontam para grupos separados, mas interseccionados. Uma mesma referência pode aparecer, como de fato apareceu, em muitas outras cliques. Por isso, alguns nós parecem fazer mais sentido em outro subgrupo, como são os casos de Carvalho e Boaventura de Sousa Santos. No entanto, a interpretação aludida é a de que tais referências-chaves oferecem a ponte (intermediação) para outras linhas teóricas, ora assumidas como objetos de críticas, ora assimiladas sem maiores confrontos conceituais.

Por fim, o grafo 1 condensa os aspectos anteriores ilustrando-os: as cores distintas representam os subgrupos, as arestas mais es- 
pessas os vínculos mais fortes e o tamanho dos nós foi calculado pela centralidade de intermediação.

\section{Considerações finais}

0 atual estágio desta investigação ainda carece de maiores aprofundamentos. Convém lembrar, este texto faz parte de um projeto de pesquisa mais amplo. A análise de outras variáveis - objetos e temas de estudo, técnicas e métodos de pesquisa, etc. - sobre a produção do conhecimento em cidadania no Brasil será fundamental para aumentar o rigor interpretativo dos dados. Da mesma forma, com o incremento do corpus de análise com outras bases (teses e dissertações, por exemplo) se poderá aferir melhor os resultados até o momento alcançados. Ou seja, a partir do refinamento metodológico poder-se-á melhor visualizar as tradições de pensamento que marcam as interpretações conceituais acerca do tema aqui enfocado.

No entanto, com base nos dados coligidos e reconhecendo os limites da pesquisa, foram feitos alguns achados: a produção acadêmica sobre cidadania, desde 1992, tem sido ascendente, com um pico no ano de 2008 ocasionado pela aglutinação dos estudos da área da saúde. 0 predomínio dos autores é do gênero feminino (quase 60\%), e levando em conta este dado há que se ressaltar o pouco volume de estudos que explorem as assimetrias entre os sexos. É possível localizar geograficamente (SP, RJ, DF e RS) e institucionalmente (UNICAMP, FIOCRUZ, USP, UNESP e UFRGS) as revistas especializadas que recebem artigos com a temática em apreço. Com relação aos autores dos trabalhos, praticamente ocorre o mesmo, com pouca variação. Há uma aglutinação geográfica (SP, RJ e DF) e institucional (USP, UNB, UNICAMP, UFSCAR, UFRJ). A aglutinação também ocorre por áreas do conhecimento, tanto das revistas quanto dos autores dos trabalhos (Saúde, Ciências Sociais e Educação). 
Em relação ao conteúdo, as palavras-chaves e títulos dos artigos revelam que, no período aqui analisado, a cidadania é fortemente associada ao termo "educação". Tal fato parece demonstrar a ideia subjacente de que inexiste cidadania sem processos educativos e formativos. A presença forte do termo "saúde" também sugere que os pesquisadores voltam seus estudos mais para a dimensão social dos direitos, refletindo a conexão existente entre os textos acadêmicos e seus respectivos contextos sociais. Isto porque as publicações brasileiras - ao menos, a parte presente no Scielo -, interessadas em alguma medida no debate acerca da cidadania, parecem reconhecer os problemas nacionais em relação aos sistemas de saúde e educacional (direitos sociais que deveriam ser básicos), os quais impedem o acesso à cidadania para grande parte da população. Em contrapartida, a presença forte do termo "participação" indica que boa parte desta mesma produção do conhecimento concebe que a cidadania, para ser alcançada, necessita de tal componente. Aquela seria uma condição para esta.

Quando feita a apreciação das listas de referências bibliográficas, percebe-se que em sua maioria são autores transacionados nas Ciências Sociais. Contudo, a ausência de um autor fortemente marxista não é algo que passa despercebida, uma vez que o capitalismo impõe severas restrições para que os indivíduos tornem-se sujeitos de direito. 0 nome, por exemplo, de Décio Saes (2001) - autor marxista que contribuiu substancialmente para o debate crítico da cidadania no Brasil - aparece muito timidamente e não figura entre os mais citados.

Mas se este estudo não conseguiu alcançar uma conclusão definitiva, ao menos serviu para criar hipóteses para num futuro próximo serem testadas. Como, por exemplo, a de que as subdivisões teóricas do campo em apreço podem ser alavancadas pelas áreas do conhecimento (o que também pode ser apoiada pelas palavras-chaves mais freqüentes). Com isso, cada área do conhecimento apresentaria os seus próprios próceres nos estu- 
dos políticos e sociais. Os nomes de Foucault e Morin como referências-chaves poderiam ser explicados por esta ótica. Outra hipótese é a que sugere que as interpretações acerca da cidadania no Brasil são fomentadas por perspectivas mais amplas que a do modelo da "marcha dos direitos". 0 forte apelo à educação e participação nas nuvens de palavras, bem como a presença de referências-chaves como Boaventura de Sousa Santos, Habermas, Tourraine, Gonh, Dagnino, Avritzer, entre outros, indica esse caminho.

De todo modo, usando a expressão de Koselleck (2006), não há motivos para acreditar que o horizonte de expectativas da cidadania no Brasil escape ao espaço de experiências aqui apresentado. 0 léxico que discutirá o conceito de cidadania, e com isso as próprias práticas de cidadania, será oferecido pelas perspectivas delineadas, que são mobilizadas pela comunidade científica, enquadrada não como distante dos conflitos que atravessam a sociedade, blindada pela neutralidade científica. Mas, ao contrário, enquanto formada por redatores que contestam ou legitimam as representações sociais que contribuem para construir.

\section{Referências Bibliográficas}

a) LIVROS

BOTTOMORE, Tom. Citizenship and social class, forty years on. In: MARSHALL, Thomas H; BOTTOMORE, Tom. Citizenship and social class. Londres: Pluto Press, 1992 [1950].

CARVALHO, José Murilo de. Cidadania no Brasil: 0 longo caminho. Rio de Janeiro: Civilização Brasileira, 2001.

KOSELLECK, Reinhart. Futuro Passado: contribuição à semântica dos tempos históricos. Rio de Janeiro: Contraponto, Ed. PUC-Rio, 2006.

MARSHALL, Thomas H. Cidadania, Classe Social e Status. Rio de Janeiro: Zahar, 1967 [1949]. 
MELO, Manuel P. da Cunha e. Quem Explica o Brasil. Juiz de Fora: Editora UFJF; 1999.

SANTOS, Wanderley G dos. Cidadania e Justiça: A política social na ordem brasileira. Rio de Janeiro: Campus, 1987.

SOUZA, Jessé. A construção social da subcidadania: Para uma sociologia política da modernidade periférica. Belo Horizonte: Editora UFMG, 2006.

b) ARTIGOS DE PERIÓDICOS

MAINWARING, Scott; SHARE, Donald. Transição por transação: democratização no Brasil e na Espanha. Dados, Rio de Janeiro, v. 29, n.2, p. 207-236, 1986.

SAES, Décio. A questão da evolução da cidadania política no Brasil. Estudos Avançados, São Paulo, 15 (42), p. 379-410, 2001.

SOMERS, Margaret. Citizenship and the place of the public sphere: Law, community, and political culture in the transition to democracy. American Sociological Review, Chicago, v. 58, p. 587-620, out. 1993.

TAVOLARO, Sergio B. F. Quando discursos e oportunidades políticas se encontram: Para repensar a sociologia política da cidadania moderna. Novos Estudos, Cebrap, n. 81, p. 117-136, 2008.

. Para além de uma 'cidadania à brasileira': Uma consideração crítica da produção sociológica nacional. Revista de Sociologia e Política, Curitiba, v. 17, n. 32, pp. 95-120, 2009.

c) COLETÂNEA

PINSKY, Jaime; PINSKY, Carla B. (Orgs.). História da Cidadania. São Paulo, Ed. Contexto, 2003.

RICHTER, Melvin. Avaliando um clássico contemporâneo: o Geschichtliche Grundbegriffe e a atividade acadêmica futura. In: JASMIN, Marcelo G; FERES JÚNIOR, João. (orgs.) História dos conceitos: debates e perspectivas. Rio de Janeiro: Editora PUC-Rio: Edições Loyola, 2006.

\section{Anexo - Corpus de Análise}

ABICAIL, Carlos Augusto. Direitos humanos e cidadania: a educação como campo de conflito. Rev. Bras. Educ. [online]. 2002, n.19, pp. 138-147.

ACIOLE, Giovanni Gurgel. Das dimensões pedagógicas para a construção da cidadaniano exercício do controle social. Interface (Botucatu) [online]. 2007, vol.11, n.23, pp. 409-426. 
ADDISON BARACCHINI, Sabrina. A inovação presente na administração pública brasileira. Rev. adm. empres. [online]. 2002, vol.42, n.2, pp. 1-6.

AFONSO, Almerindo Janela and ANTUNES, Fátima. Educação, cidadania e competividade: questões em torno de uma nova agenda. Cad. Pesqui. [online]. 2001, n.113, pp. 83-112.

ALBERNAZ, Renata Ovenhausen and AZEVEDO, Ariston. Pluralização societária e os desafios à administração pública na América Latina. Soc. estado. [online]. 2011, vol.26, n.2, pp. 329-352.

ALLEBRANDT, Sérgio Luís; SIEDENBERG, Dieter Rugard; SAUSEN, Jorge Oneide and DECKERT, Cristiele Tomm. Gestão social e cidadania deliberativa: uma análise da experiência dos Coredes no Rio Grande do Sul, 1990-2010. Cad. EBAPE.BR [online]. 2011, vol.9, n.3, pp. 914-945.

ALVAREZ, Aparecida Magali de Souza; ALVARENGA, Augusta Thereza de and DELLA RINA, Silvia Cristiane de S. A.. Histórias de vida de moradores de rua, situações de exclusão social e encontros transformadores. Saude soc. [online]. 2009, vol.18, n.2, pp. 259-272.

ALVES, J. A. Lindgren. Direitos humanos, cidadadania e globalização. Lua Nova [online]. 2000, n.50, pp. 185-206. ISSN 0102-6445.

ALVES, Lauro Eduardo Soutello. Governança e cidadania empresarial. Rev. adm. empres. [online]. 2001, vol.41, n.4, pp. 78-86.

AMES, José Luiz. Maquiavel e a educação: a formação do bom cidadão. Trans/ Form/Ação [online]. 2008, vol.31, n.2, pp. 137-152.

ANDRADE, Angela Nobre de. A criança na sociedade contemporânea: do 'ainda não' ao cidadão em exercício. Psicol. Reflex. Crit. [online]. 1998, vol.11, n.1, pp. 161-174.

ARAUJO, Eliany Alvarenga de. Informação, sociedade e cidadania: gestão da informação no contexto de organizações não-governamentais (ONGs) brasileiras. Ci. Inf. [online]. 1999, vol.28, n.2, pp. 155-167.

AREJANO, Ceres Braga; PADILHA, Maria Itayra Coelho de Souza and ALBUQUERQUE, Gelson Luiz de. Reforma psiquiátrica: uma analítica das relações de poder nos serviços de atenção à Saúde Mental. Rev. bras. enferm. [online]. 2003, vol.56, n.5, pp. 549-554.

ASSIS, Luiz Fernandes de. Educando para a cidadania: a experiência da escola do Legislativo. Educ. Soc. [online]. 1997, vol.18, n.59, pp. 369-387.

AZEVEDO, Celia Maria Marinho de. A recusa da "raça": anti-racismo e cidadania no Brasil dos anos 1830. Horiz. antropol. [online]. 2005, vol.11, n.24, pp. 297-320. 
BAGGIO, Rodrigo. A sociedade da informação e a infoexclusão. Ci. Inf. [online]. 2000, vol.29, n.2, pp. 16-21.

BARBOSA, Regina Simões and GIFFIN, Karen. Gênero, saúde reprodutiva e vida cotidiana em uma experiência de pesquisa-ação com jovens da Maré, Rio de Janeiro. Interface (Botucatu) [online]. 2007, vol.11, n.23, pp. 549-567.

BARRETO, Jubel. Cidadania, subjetividade e Reforma Psiquiátrica. Physis [online]. 2008, vol.18, n.2, pp. 295-316.

BASILE, Marcello. Revolta e cidadania na Corte regencial. Tempo [online]. 2007, vol.11, n.22, pp. 31-57.

BELLATO, Roseney and GAIVA, Maria Aparecida Munhoz. A cidadania e a ética como eixos norteadores da formacão do enfermeiro. Rev. bras. enferm. [online]. 2003, vol.56, n.4, pp. 429-432.

BELLATO, Roseney and PEREIRA, Wilza Rocha. 0 gerenciamento em enfermagem frente a pauperização das condições materiais de trabalho. Rev. bras. enferm. [online]. 2004, vol.57, n.4, pp. 479-483.

BENGOCHEA, Jorge Luiz Paz; GUIMARAES, Luiz Brenner; GOMES, Martin Luiz and ABREU, Sérgio Roberto de. A transição de uma polícia de controle para uma polícia cidadã. São Paulo Perspec. [online]. 2004, vol.18, n.1, pp. 119-131.

BERNARDES, Anita Guazzelli and GUARESCHI, Neuza Maria de Fátima. Dever do Estado: metamorfoses da publicização da existência e produção de subjetividades. Ciênc. saúde coletiva [online]. 2010, vol.15, suppl.1, pp. 967-976.

BIAGGIO, Angela Maria Brasil. Kohlberg e a "Comunidade Justa”: promovendo o senso ético e a cidadania na escola. Psicol. Reflex. Crit. [online]. 1997, vol.10, n.1, pp. 47-69.

BODSTEIN, Regina Cele de A.. Cidadania e modernidade: emergência da questão social na agenda pública. Cad. Saúde Pública [online]. 1997, vol.13, n.2, pp. 185-193.

BOGHOSSIAN, Cynthia Ozon and MINAYO, Maria Cecília de Souza. Revisão sistemática sobre juventude e participação nos últimos 10 anos. Saude soc. [online]. 2009, vol.18, n.3, pp. 411-423.

BORTOLOZZI, Arlêude and PEREZ FILHO, Archimedes. Diagnóstico da Educação Ambiental no ensino de Geografia: Piracicaba, Capivari and Jundiaí hidrographic basins. Cad. Pesqui. [online]. 2000, n.109, pp. 145-171.

BOSI, Maria Lúcia M.. Cidadania, participação popular e saúde na visão dos profissionais do setor: um estudo de caso na rede pública de serviços. Cad. Saúde Pública [online]. 1994, vol.10, n.4, pp. 446-456. 
BRITO, MARIA NOEMI CASTILHOS. Gênero e cidadania: referenciais analíticos. Rev. Estud. Fem. [online]. 2001, vol.9, n.1, pp. 291-298.

BRITO, Raquel Cardoso and FIGUEIREDO, Ângela Leggerini de. Desenvolvimento comunitário: uma experiência de parceria. Psicol. Reflex. Crit. [online]. 1997, vol.10, n.1, pp. 181-191.

BRUMER, Anita; PAVEI, Katiuci and MOCELIN, Daniel Gustavo. Saindo da "escuridão": perspectivas da inclusão social, econômica, cultural e política dos portadores de deficiência visual em Porto Alegre. Sociologias [online]. 2004, n.11, pp. 300-327.

BYDLOWSKI, Cynthia Rachid; LEFEVRE, Ana Maria Cavalcanti and PEREIRA, Isabel Maria Teixeira Bicudo. Promoção da saúde e a formação cidadã: a percepção do professor sobre cidadania. Ciênc. saúde coletiva [online]. 2011, vol.16, n.3, pp. 1771-1780.

CABRAL, Manuel Villaverde. 0 exercício da cidadania política em perspectiva histórica (Portugal e Brasil). Rev. bras. Ci. Soc. [online]. 2003, vol.18, n.51, pp. 31-60.

CAMPOS, Tatiane Neme; DEL PRETTE, Zilda Aparecida Pereira and DEL PRETTE, Almir. (Sobre)vivendo nas ruas: habilidades sociais e valores de crianças e adolescentes. Psicol. Reflex. Crit. [online]. 2000, vol.13, n.3, pp. 517-527.

CANEN, Ana. Educação multicultural, identidade nacional e pluralidade cultural: tensões e implicações curriculares. Cad. Pesqui. [online]. 2000, n.111, pp. 135-149.

CAPUANO, Ethel Airton. Construtos para modelagem de organizações fundamentadas na informação e no conhecimento no serviço público brasileiro. Ci. Inf. [online]. 2008, vol.37, n.3, pp. 18-37.

CARRARA, Kester and BETETTO, Mariana de Freitas. Formação ética para a cidadania: uma investigação de habilidades sociais medidas pelo inventário de habilidades sociais. Estud. psicol. (Campinas) [online]. 2009, vol.26, n.3, pp. 337-347.

CARUSO, Francisco and SILVEIRA, Cristina. Quadrinhos para a cidadania. Hist. cienc. saude-Manguinhos [online]. 2009, vol.16, n.1, pp. 217-236.

CHELIUS, Leticia Calderón. 0 que há por trás do direito ao voto dos emigrantes internacionais? Teoria, história e cidadania demandante. Contexto int. [online]. 2011, vol.33, n.1, pp. 231-250.

CONCHA-EASTMAN, Alberto and MALO, Miguel. Da repressão à prevenção da violência: desafio para a sociedade civil e para o setor saúde. Ciênc. saúde coletiva [online]. 2006, vol.11, suppl., pp. 1179-1187. 
COSTA, Daniela Viegas da and TEODOSIO, Armindo dos Santos de Sousa. Desenvolvimento sustentável, consumo e cidadania: um estudo sobre a (des)articulação da comunicação de organizações da sociedade civil, do estado e das empresas. RAM, Rev. Adm. Mackenzie (Online) [online]. 2011, vol.12, n.3, pp. 114-145.

COSTA, Naldson Ramos da. Ofício de polícia, violência policial e luta por cidadania em Mato Grosso. São Paulo Perspec. [online]. 2004, vol.18, n.1, pp. 111-118.

COTTA, Rosângela Minardi Mitre et al. O controle social em cena: refletindo sobre a participação popular no contexto dos Conselhos de Saúde. Physis [online]. 2011, vol.21, n.3, pp. 1121-1138.

COUTINHO, Renata Buarque Goulart and MACEDO-SOARES, T. Diana L. v. A.. Gestão estratégica com responsabilidade social: arcabouço analítico para auxiliar sua implementação em empresas no Brasil. Rev. adm. contemp. [online]. 2002, vol.6, n.3, pp. 75-96.

CURY, Carlos Roberto Jamil. Políticas inclusivas e compensatórias na educação básica. Cad. Pesqui. [online]. 2005, vol.35, n.124, pp. 11-32.

DESAULNIERS, Julieta Beatriz Ramos. Formação, competência e cidadania. Educ. Soc. [online]. 1997, vol.18, n.60, pp. 51-63.

DESAULNIERS, Julieta Beatriz Ramos. Memória social e cidadania. Cad. CEDES [online]. 1997, vol.18, n.42, pp. 93-107.

DIETZSCH, Mary Julia Martins. Leituras da cidade e educação. Cad. Pesqui. [online]. 2006, vol.36, n.129, pp. 727-759.

DOLHNIKOFF, Miriam. Império e governo representativo: uma releitura. Cad. CRH [online]. 2008, vol.21, n.52, pp. 13-23.

DORIA, Carlos and TUBINO, Manoel José Gomes. Avaliação da busca da cidadania pelo Projeto Olímpico da Mangueira. Ensaio: aval.pol.públ.Educ. [online]. 2006, vol.14, n.50, pp. 77-90.

DUARTE, Adriano Luiz. "Em busca de um lugar no mundo": movimentos sociais e política na cidade de São Paulo nas décadas de 1940 e 50. Estud. hist. (Rio J.) [online]. 2008, vol.21, n.42, pp. 195-219.

DUARTE, Adriano Luiz. Moralidade pública e cidadania: a educação nos anos 30 e 40. Educ. Soc. [online]. 2000, vol.21, n.73, pp. 165-181.

DUARTE, Newton. Limites e contradições da cidadania na sociedade capitalista. Pro-Posições [online]. 2010, vol.21, n.1, pp. 75-87.

ESTEVAO, Carlos V.. FORMAÇÃO, GESTÃO, TRABALHO E CIDADANIA CONTRIBUTOS PARA UMA SOCIOLOGIA CRÍTICA DA FORMAÇÃO. Educ. Soc. [online]. 2001, vol.22, n.77, pp. 185-206. 
FAVA-DE-MORAES, FLAVIO and MARTINEZ SOTO, MARIA JOSEFA DEL CARMEN. Informação e conhecimento no setor público: a experiência da Fundação SEADE. São Paulo Perspec. [online]. 2002, vol.16, n.3, pp. 15-22.

FERNANDES, Josicelia Dumêt; OLIVEIRA, Maria Rita and FERNANDES, Juliana. Cidadania e qualidade de vida dos portadores de transtornos psiquiátricos: contradições e racionalidade. Rev. esc. enferm. USP [online]. 2003, vol.37, n.2, pp. 35-42.

FERNANDES, Paula T. et al. Grupos de Interação Social (GIS): estratégia de empowerment para pessoas com epilepsia. J. epilepsy clin. neurophysiol. [online]. 2011, vol.17, n.2, pp. 70-74.

FERREIRA, Naura Syria Carapeto. Repensando e ressignificando a gestão democrática da educação na "cultura globalizada". Educ. Soc. [online]. 2004, vol.25, n.89, pp. 1227-1249.

FLEURY, Sonia. Reforma sanitária brasileira: dilemas entre o instituinte e o instituído. Ciênc. saúde coletiva [online]. 2009, vol.14, n.3, pp. 743-752.

FONSECA, Francisco. Democracia e participação no Brasil: descentralização e cidadania face ao capitalismo contemporâneo. Rev. katálysis [online]. 2007, vol.10, n.2, pp. 245-255.

FRANCA, Antonio Carlos de Souza Leão Galvão. A saúde mental e a subjetividade-cidadã. Fractal, Rev. Psicol. [online]. 2008, vol.20, n.1, pp. 129-133.

FREIRE, Isa Maria; NOBREGA, Nanci Gonçalves da; BADINI, Sandra Borges and ARAUJO, Vânia Maria Rodrigues Hermes de. Ação de informação para cidadania: biblioteca e arquivo escolar. Perspect. ciênc. inf. [online]. 2009, vol.14, n.1, pp. 117-130.

GALLO, Sílvio and ASPIS, Renata Lima. Ensino de filosofia e cidadania nas "sociedades de controle": resistência e linhas de fuga. Pro-Posições [online]. 2010, vol.21, n.1, pp. 89-105.

GARCIA, Afrânio. A sociologia rural no Brasil: entre escravos do passado e parceiros do futuro. Sociologias [online]. 2003, n.10, pp. 154-189.

GOHN, Maria da Glória. Movimentos sociais na contemporaneidade. Rev. Bras. Educ. [online]. 2011, vol.16, n.47, pp. 333-361.

GOMES, Tiago de Melo. Negros contando (e fazendo) sua história: alguns significados da trajetória da Companhia Negra de Revistas (1926). Estud. afro-asiát. [online]. 2001, vol.23, n.1, pp. 53-83.

GOTO, Roberto. 0 cidadão Sócrates e o filosofar numa democracia. Pro-Posições [online]. 2010, vol.21, n.1, pp. 107-125. 
GOULART, Flavio A. A.. Representações sociais, ação política e cidadania. Cad. Saúde Pública [online]. 1993, vol.9, n.4, pp. 477-486.

GUIMARAES, José Maria Ximenes et al. Participação social na saúde mental: espaço de construção de cidadania, formulação de políticas e tomada de decisão. Ciênc. saúde coletiva [online]. 2010, vol.15, n.4, pp. 2113-2122.

GUIMARAES, Katia and MERCHAN-HAMANN, Edgar. Comercializando fantasias: a representação social da prostituição, dilemas da profissão e a construção da cidadania. Rev. Estud. Fem. [online]. 2005, vol.13, n.3, pp. 525-544.

HADDAD, Eneida Gonçalves de Macedo and SINHORETTO, Jacqueline. Centros de Integração da Cidadania: democratização do sistema de justiça ou o controle da periferia?. São Paulo Perspec. [online]. 2004, vol.18, n.1, pp. 72-76.

HELLER, Léo and CASTRO, José Esteban. Política pública de saneamento: apontamentos teórico-conceituais. Eng. Sanit. Ambient. [online]. 2007, vol.12, n.3, pp. 284-295.

IIZUKA, Edson Sadao; GONCALVES-DIAS, Sylmara Lopes Francelino and AGUERRE, Pedro. Gestão social e cidadania deliberativa: a experiência de Ilha Comprida - São Paulo. Cad. EBAPE.BR [online]. 2011, vol.9, n.3, pp. 748-779.

IVO, Anete B. L.. Georg Simmel e a "sociologia da pobreza". Cad. CRH [online]. 2008, vol.21, n.52, pp. 171-180.

JACOBI, Pedro R.. Políticas sociais locais e os desafios da participação citadina. Ciênc. saúde coletiva [online]. 2002, vol.7, n.3, pp. 443-454.

JACOBI, Pedro Roberto. Educação, ampliação da cidadania e participação. Educ. Pesqui. [online]. 2000, vol.26, n.2, pp. 11-29.

JACOBI, Pedro Roberto. Espaços públicos e práticas participativas na gestão do meio ambiente no Brasil. Soc. estado. [online]. 2003, vol.18, n.1-2, pp. 315-338.

JACOBI, Pedro Roberto. Estado e educação: o desafio de ampliar a cidadania. Educ. rev. [online]. 2008, n.31, pp. 113-127.

JACOBI, Pedro. Educação ambiental, cidadania e sustentabilidade. Cad. Pesqui. [online]. 2003, n.118, pp. 189-206.

JACOBI, Pedro. Poder local, políticas sociais e sustentabilidade. Saude soc. [online]. 1999, vol.8, n.1, pp. 31-48.

KARAM, Heliete. 0 sujeito entre a alcoolização e a cidadania: perspectiva clínica do trabalho. Rev. psiquiatr. Rio Gd. Sul [online]. 2003, vol.25, n.3, pp. 468474. 
KLIGERMAN, Débora Cynamon et al. A experiência do Programa Universidade Aberta e suas contribuições para a transformação social. Ciênc. saúde coletiva [online]. 2005, vol.10, suppl., pp. 195-205.

KRAWCZYK, Nora Rut. Políticas de regulação e mercantilização da educação: socialização para uma nova cidadania?. Educ. Soc. [online]. 2005, vol.26, n.92, pp. 799-819.

KRISCHKE, Paulo J.. A cultura política em Porto Alegre e Curitiba: democracia, modernização e o conteúdo da razão pública. Soc. estado. [online]. 2005, vol.20, n.1, pp. 39-71.

KUSTER, Eliana and PECHMAN, Robert Moses. Da ordem. Da cidade. Da literatura: personagens à beira do "ruim do mundo". Soc. estado. [online]. 2007, vol.22, n.3, pp. 593-620.

LAMPERT, Ernani. Educação e Mercosul: desafios e perspectivas. Rev. Fac. Educ. [online]. 1998, vol.24, n.2, pp. 9-28.

LARA, Marilda Lopes Ginez de and CONTI, Vivaldo Luiz. Disseminação da informação e usuários. São Paulo Perspec. [online]. 2003, vol.17, n.3-4, pp. 26-34.

LAVALLE, Adrián Gurza. Cidadania, igualdade e diferença. Lua Nova [online]. 2003, n.59, pp. 75-93.

LECHNER, Norbert. Os novos perfis da política: um esboço. Lua Nova [online]. 2004, n.62, pp. 5-20.

LEITE, Lidiane and ARAGAO, Elizabeth Maria Andrade. 0 exercício ético na constituição do sujeito político como cidadão. Fractal, Rev. Psicol. [online]. 2010, vol.22, n.3, pp. 543-556.

LEITE, Márcia Pereira. Entre o individualismo e a solidariedade: dilemas da política e da cidadania no Rio de Janeiro. Rev. bras. Ci. Soc. [online]. 2000, vol.15, n.44, pp. 43-90.

LEITE, Silvana Nair and TONOLLI, Lirya Liz Monteiro. Uma terceira via para a gente aprender as coisas femininas... perspectivas sobre o desenvolvimento de um projeto de promoção de saúde e cidadania de meninas. Interface (Botucatu) [online]. 2010, vol.14, n.35, pp. 933-942. Epub Aug 06, 2010.

LIMA, Clarisse O. and BROWN, Scott W.. Global citizenship and new literacies providing new ways for social inclusion. Psicol. Esc. Educ. (Impr.) [online]. 2007, vol.11, n.1, pp. 13-20.

LIMA, Gustavo da Costa. Questão ambiental e educação: contribuições para o debate. Ambient. soc. [online]. 1999, n.5, pp. 135-153. 
LONGHI, Jean Camargo and CANTON, Giselle Alice Martins. Reflexões sobre cidadania e os entraves para a participação popular no SUS. Physis [online]. 2011, vol.21, n.1, pp. 15-30.

LOPES, Roseli Esquerdo et al. Juventude pobre, violência e cidadania. Saude soc. [online]. 2008, vol.17, n.3, pp. 63-76.

LOPES, Roseli Esquerdo et al. Oficinas de atividades com jovens da escola pública: tecnologias sociais entre educação e terapia ocupacional. Interface (Botucatu) [online]. 2011, vol.15, n.36, pp. 277-288.

LOREA, Roberto Arriada. Acesso ao casamento no Brasil: uma questão de cidadania sexual. Rev. Estud. Fem. [online]. 2006, vol.14, n.2, pp. 488-496.

MACEDO, Maria Joacineide de and BRITO, Suerde Miranda de Oliveira. A luta pela cidadania dos meninos do Movimento Nacional de Meninos e Meninas de Rua: uma ideologia reconstrutora. Psicol. Reflex. Crit. [online]. 1998, vol.11, n.3, pp. 511-522.

MACHADO, Carlos José Saldanha. Recursos hídricos e cidadania no Brasil: limites, alternativas e desafios. Ambient. soc. [online]. 2003, vol.6, n.2, pp. 121-136.

MAGALHAES, Rosana et al. A implementação do programa Bolsa Família: as experiências de São Francisco de Itabapoana e Duque de Caxias. Ciênc. saúde coletiva [online]. 2007, vol.12, n.6, pp. 1513-1524.

MAGALHAES, Rosana. Enfrentando a pobreza, reconstruindo vínculos sociais: as lições da Ação da Cidadania contra a Fome, a Miséria e pela Vida. Cad. Saúde Pública [online]. 2002, vol.18, suppl., pp. S121-S137.

MARQUES, Denise Travassos and PACHANE, Graziela Giusti. Formação de educadores: uma perspectiva de educação de idosos em programas de EJA. Educ. Pesqui. [online]. 2010, vol.36, n.2, pp. 475-490.

MARTINS, Poliana Cardoso et al. Conselhos de saúde e a participação social no Brasil: matizes da utopia. Physis [online]. 2008, vol.18, n.1, pp. 105-121.

MATA, José Veríssimo Teixeira da. Os limites da soberania em Rousseau. Trans/ Form/Ação [online]. 1995, vol.18, pp. 95-104.

MATOS, Nelson Dagoberto de. A política de educação especial no estado de Sergipe (1979-2001). Rev. bras. educ. espec. [online]. 2007, vol.13, n.1, pp. 77-94.

MATTOZZI, Ivo. Currículo de História e educação para o patrimônio. Educ. rev. [online]. 2008, n.47, pp. 135-155.

MAZZARINO, Jane M. et al. Daily practices, consumption and citizenship. An. Acad. Bras. Ciênc. [online]. 2011, vol.83, n.4, pp. 1481-1492. Epub Oct 21, 2011. 
MAZZARINO, Jane. Matrizes que se cruzam: interações entre movimento socioambiental e campo jornalístico. Ambient. soc. [online]. 2008, vol.11, n.1, pp. 49-66.

MEDEIROS, Soraya Maria de and GUIMARAES, Jacileide. Cidadania e saúde mental no Brasil: contribuição ao debate. Ciênc. saúde coletiva [online]. 2002, vol.7, n.3, pp. 571-579.

MELLO, Luiz. Familismo (anti)homossexual e regulação da cidadania no Brasil. Rev. Estud. Fem. [online]. 2006, vol.14, n.2, pp. 497-508.

MISKOLCI, Richard. Uma brasileira: a outra história de Julia Mann. Cad. Pagu [online]. 2003, n.20, pp. 157-176.

MOISES, José Álvaro. Cidadania, confiança e instituições democráticas. Lua Nova [online]. 2005, n.65, pp. 71-94.

MOISES, José Álvaro. Cultura política, instituições e democracia: lições da experiência brasileira. Rev. bras. Ci. Soc. [online]. 2008, vol.23, n.66, pp. 11-43.

MONTEIRO, Linderval Augusto. Invisibilidade social e reação popular em uma favela da Baixada Fluminense: o caso Nova Jerusalém. Tempo [online]. 2012, vol.17, n.31, pp. 231-260.

MORGADO, Miguel. O Poder Judicial na sociedade livre. Rev. katálysis [online]. 2006, vol.9, n.1, pp. 75-84.

MOTA, Kelly Cristine Corrêa da Silva. Os lugares da sociologia na formação de estudantes do ensino médio: as perspectivas de professores. Rev. Bras. Educ. [online]. 2005, n.29, pp. 88-107.

MOULIN, Carolina. Os direitos humanos dos humanos sem direitos: refugiados e a política do protesto. Rev. bras. Ci. Soc. [online]. 2011, vol.26, n.76, pp. 145155.

MOURA, Erly Catarina. Direito a saúde: o papel de diferentes sujeitos sociais no exercício da cidadania. Saude soc. [online]. 1996, vol.5, n.1, pp. 101-119.

NEVES, Lúcia Maria Bastos P.. Cidadania e participação política na época da Independência do Brasil. Cad. CEDES [online]. 2002, vol.22, n.58, pp. 47-64.

NUNES, Edison; SANCHES, Félix and CHAIA, Vera. Cultura política e valores de cidadania na Região Metropolitana de São Paulo. Opin. Publica [online]. 2010, vol.16, n.2, pp. 478-515.

NUNES, Márcia Vidal. As rádios comunitárias nas campanhas eleitorais: exercício da cidadania ou instrumentalização (1998-2000). Rev. Sociol. Polit. [online]. 2004, n.22, pp. 59-76. 
OLIVEIRA FILHO, João Pacheco de. Cidadania e globalização: povos indígenas e agências multilaterais. Horiz. antropol. [online]. 2000, vol.6, n.14, pp. 125-141.

OLIVEIRA, Alice Guimarães Bottaro de and ALESSI, Neiry Primo. Cidadania: instrumento e finalidade do processo de trabalho na reforma psiquiátrica. Ciênc. saúde coletiva [online]. 2005, vol.10, n.1, pp. 191-203.

OLIVEIRA, Antonio. Os policiais podem ser controlados?. Sociologias [online]. 2010, n.23, pp. 142-175.

OLIVEIRA, Luís R. Cardoso de. Racismo, direitos e cidadania. Estud. av. [online]. 2004, vol.18, n.50, pp. 81-93.

OLIVEIRA, Luiz Antonio Pinto de and SIMOES, Celso Cardoso da Silva. O IBGE e as pesquisas populacionais. Rev. bras. estud. popul. [online]. 2005, vol.22, n.2, pp. 291-302.

ORTIZ, Leodi Conceição Meireles et al. A classe hospitalar como instrumento de participação política na construção coletiva da associação de pais e pacientes da hematooncologia. Educ. rev. [online]. 2010, vol.26, n.2, pp. 317-335.

OTTMANN, Goetz. Cidadania mediada: processos de democratização da política municipal no Brasil. Novos estud. - CEBRAP [online]. 2006, n.74, pp. 155175.

OXHORN, Philip. Cidadania como consumo ou cidadania como agência: uma comparação entre as reformas de democratização da Bolívia e do Brasil. Sociologias [online]. 2010, vol.12, n.24, pp. 18-43.

PAIVA, Denise; SOUZA, Marta Rovery and LOPES, Gustavo de Faria. As percepções sobre democracia, cidadania e direitos. Opin. Publica [online]. 2004, vol.10, n.2, pp. 368-376.

PARRAT-DAYAN, Silvia. A discussão como ferramenta para o processo de socialização e para a construção do pensamento. Educ. rev. [online]. 2007, n.45, pp. 13-23.

PEREIRA, José Roberto et al. Gestão social dos territórios da cidadania: o zoneamento ecológico-econômico como instrumento de gestão do território noroeste de Minas Gerais. Cad. EBAPE.BR [online]. 2011, vol.9, n.3, pp. 724747.

PEREIRA, Sueli Menezes. Políticas de Estado e organização político-pedagógica da escola: entre o instituído e o instituinte. Ensaio: aval.pol.públ.Educ. [online]. 2008, vol.16, n.60, pp. 337-358.

PEREIRA, Tatiana Dahmer. Política Nacional de Assistência Social e território: enigmas do caminho. Rev. katálysis [online]. 2010, vol.13, n.2, pp. 191-200. 
PEREZ, Beatriz Corsino; POVOA, Juliana; MONTEIRO, Renata and CASTRO, Lucia Rabello de. Cidadania e participação social: um estudo com crianças no Rio de Janeiro. Psicol. Soc. [online]. 2008, vol.20, n.2, pp. 181-191.

PEREZ, José Roberto Rus and PASSONE, Eric Ferdinando. Políticas sociais de atendimento às crianças e aos adolescentes no Brasil. Cad. Pesqui. [online]. 2010, vol.40, n.140, pp. 649-673.

PIASSI, Luís Paulo. Educação científica no ensino fundamental: os limites dos conceitos de cidadania e inclusão veiculados nos PCN. Ciênc. educ. (Bauru) [online]. 2011, vol.17, n.4, pp. 789-805.

PONTES, Reinaldo Nobre. Concepções de pobreza dos atores sociais na política de assistência social no período FHC. Rev. katálysis [online]. 2010, vol.13, n.2, pp. 181-190.

PORTO, Juliana Barreiros and TAMAYO, Álvaro. Desenvolvimento e validação da escala de civismo nas organizações. Estud. psicol. (Natal) [online]. 2003, vol.8, n.3, pp. 393-402.

PORTO, Juliana Barreiros and TAMAYO, Álvaro. Valores organizacionais e civismo nas organizações. Rev. adm. contemp. [online]. 2005, vol.9, n.1, pp. 3552.

REGO, Arménio. Climas éticos e comportamentos de cidadania organizacional. Rev. adm. empres. [online]. 2002, vol.42, n.1, pp. 1-14.

REGO, Walquiria Leão. Lua Nova [online]. 2008, n.73, pp. 147-185.

REIGOTA, Marcos Antonio dos Santos. Cidadania e educação ambiental. Psicol. Soc. [online]. 2008, vol.20, n.spe, pp. 61-69.

RIBEIRO, Gladys Sabina. Cidadania e luta por direitos na Primeira República: analisando processos da Justiça Federal e do Supremo Tribunal Federal. Tempo [online]. 2009, vol.13, n.26, pp. 101-117.

RIBEIRO, Luiz Cesar Queiróz. Desafios da construção da cidadania na metrópole brasileira. Soc. estado. [online]. 2007, vol.22, n.3, pp. 525-544.

RIBEIRO, Marlene. Educação para a cidadania: questão colocada pelos movimentos sociais. Educ. Pesqui. [online]. 2002, vol.28, n.2, pp. 113-128.

RICCI, Magda. Cabanagem, cidadania e identidade revolucionária: o problema do patriotismo na Amazônia entre 1835 e 1840. Tempo [online]. 2007, vol.11, n.22, pp. 5-30.

RIZZINI, Irene; PEREIRA, Luciléia and THAPLIYAL, Nisha. Percepções e experiências de participação cidadã de crianças e adolescentes no Rio de Janeiro. Rev. katálysis [online]. 2007, vol.10, n.2, pp. 164-177. 
ROCHA, Juliana Ferreira da and CARRARA, Kester. Formação ética para a cidadania: reorganizando contingências na interação professor-aluno. Psicol. Esc. Educ. [online]. 2011, vol.15, n.2, pp. 221-230.

ROCHA, Marisa Perrone Campos. A questão cidadania na sociedade da informação. Ci. Inf. [online]. 2000, vol.29, n.1, pp. 40-45.

RODRIGUES, Ivete and BARBIERI, José Carlos. A emergência da tecnologia social: revisitando o movimento da tecnologia apropriada como estratégia de desenvolvimento sustentável. Rev. Adm. Pública [online]. 2008, vol.42, n.6, pp. 1069-1094.

RODRIGUES, Marlene Teixeira. O sistema de justiça criminal e a prostituição no Brasil contemporâneo: administração de conflitos, discriminação e exclusão. Soc. estado. [online]. 2004, vol.19, n.1, pp. 151-172.

ROTHBERG, Danilo. Por uma agenda de pesquisa em democracia eletrônica. Opin. Publica [online]. 2008, vol.14, n.1, pp. 149-172.

SAILLANT, Francine. O Navio Negreiro: refiguração identitária e escravidão no Brasil. Tempo [online]. 2010, vol.15, n.29, pp. 111-137.

SANTIN, Janaína Rigo and MARANGON, Elizete Gonçalves. 0 estatuto da cidade e os instrumentos de política urbana para proteção do patrimônio histórico: outorga onerosa e transferência do direito de construir. História [online]. 2008, vol.27, n.2, pp. 89-109.

SANTOS, Beatriz Catão Cruz. Irmandades, oficiais mecânicos e cidadania no Rio de Janeiro do século XVIII. Varia hist. [online]. 2010, vol.26, n.43, pp. 131-153.

SANTOS, Elisangela Marina dos; DUARTE, Elizabeth Andrade and PRATA, Nilson Vidal. Cidadania e trabalho na sociedade da informação: uma abordagem baseada na competência informacional. Perspect. ciênc. inf. [online]. 2008, vol.13, n.3, pp. 208-222.

SANTOS, Geovânia Lúcia dos. Educação ainda que tardia: a exclusão da escola e a reinserção de adultos das camadas populares em um programa de EJA. Rev. Bras. Educ. [online]. 2003, n.24, pp. 107-125.

SANTOS, Patrícia Oliveira; BISPO, Josiane dos Santos and OMENA, Maria Luiza Rodrigues de A.. O ensino de Ciências Naturais e cidadania sob a ótica de professores inseridos no programa de aceleração de aprendizagem da EJA Educação de Jovens e Adultos. Ciênc. educ. (Bauru) [online]. 2005, vol.11, n.3, pp. 411-426.

SANTOS, Vânia Maria Nunes dos and JACOBI, Pedro Roberto. Formação de professores e cidadania: projetos escolares no estudo do ambiente. Educ. Pesqui. [online]. 2011, vol.37, n.2, pp. 263-278. 
SANTOS, Wildson Luiz Pereira dos and MORTIMER, Eduardo Fleury. Tomada de decisão para ação social responsável no ensino de ciências. Ciênc. educ. (Bauru) [online]. 2001, vol.7, n.1, pp. 95-111.

SANTOS, Wildson Luiz Pereira dos. Educação científica na perspectiva de letramento como prática social: funções, princípios e desafios. Rev. Bras. Educ. [online]. 2007, vol.12, n.36, pp. 474-492.

SCHERER-WARREN, Ilse. Das mobilizações às redes de movimentos sociais. Soc. estado. [online]. 2006, vol.21, n.1, pp. 109-130.

SEMERARO, Giovanni. Da sociedade de massa à sociedade civil: a concepção da subjetividade em Gramsci. Educ. Soc. [online]. 1999, vol.20, n.66, pp. 65-83.

SEMINOTTI, Nedio Antonio; MORAES, Maria Lúcia Andreoli de and ROCHA, Flávia Moises. Pequenos grupos informais nas instituições: exercício da cidadania e da dimensão instituinte. Psico-USF (Impr.) [online]. 2009, vol.14, n.3, pp. 329-340.

SEVERINO, Antônio Joaquim. Educação e universidade: conhecimento e construção da cidadania. Interface (Botucatu) [online]. 2002, vol.6, n.10, pp. 117124.

SEVERINO, Antônio Joaquim. Expansão do ensino superior: contextos, desafios, possibilidades. Avaliação (Campinas) [online]. 2009, vol.14, n.2, pp. 253266.

SEVERINO, Antônio Joaquim. Formação política do adolescente no ensino médio: a contribuição da Filosofia. Pro-Posições [online]. 2010, vol.21, n.1, pp. 57-74.

SILVA, Ana Cristina Fonseca Nogueira da. Fotografando o mundo colonial africano Moçambique, 1929. Varia hist. [online]. 2009, vol.25, n.41, pp. 107-128.

SILVA, Helena; JAMBEIRO, Othon; LIMA, Jussara and BRANDAO, Marco Antônio. Inclusão digital e educação para a competência informacional: uma questão de ética e cidadania. Ci. Inf. [online]. 2005, vol.34, n.1, pp. 28-36.

SILVA, Victor Hugo da. Cidadania e inserção laboral assistida: a experiência do trabalho formal de adolescentes pobres. Estud. psicol. (Natal) [online]. 2011, vol.16, n.2, pp. 187-195.

SILVEIRA, Henrique Flávio Rodrigues da. Internet, governo e cidadania. Ci. Inf. [online]. 2001, vol.30, n.2, pp. 80-90.

SILVEIRA, Henrique Flávio Rodrigues da. Motivações e fatores críticos de sucesso para o planejamento de sistemas interorganizacionais na sociedade da informação. Ci. Inf. [online]. 2003, vol.32, n.2, pp. 107-124. 
SILVEIRA, Henrique Flávio Rodrigues da. Um estudo do poder na sociedade da informação. Ci. Inf. [online]. 2000, vol.29, n.3, pp. 79-90.

SINHORETTO, Jacqueline. Reforma da justiça: estudo de caso. Tempo soc. [online]. 2007, vol.19, n.2, pp. 157-177.

SIQUEIRA, Mirlene Maria Matias. Proposição e análise de um modelo para comportamentos de cidadania organizacional. Rev. adm. contemp. [online]. 2003, vol.7, n.spe, pp. 165-184.

SIQUEIRA, Vera Helena Ferraz de and ROCHA, Glória Walkyria de Fátima. A construção de diferenças de gênero entre estudantes de medicina. Cad. Pagu [online]. 2008, n.30, pp. 231-268.

SOBRAL, FERNANDA A. DA FONSECA. Educação para a competitividade ou para a cidadania social?. São Paulo Perspec. [online]. 2000, vol.14, n.1, pp. 03-11.

SORDI, Mara Regina Lemes De and BAGNATO, Maria Helena Salgado. Subsídios para uma formação profissional crítico-reflexiva na área da saúde: o desafio da virada do século. Rev. Latino-Am. Enfermagem [online]. 1998, vol.6, n.2, pp. 83-88.

SOUZA, Jessé. A sociologia dual de Roberto Da Matta: descobrindo nossos mistérios ou sistematizando nossos auto-enganos?. Rev. bras. Ci. Soc. [online]. 2001, vol.16, n.45, pp. 47-67.

SoUZA, Mériti de. Do terapêutico e da cidadania: leituras sobre discursos e práticas. Rev. latinoam. psicopatol. fundam. [online]. 2008, vol.11, n.3, pp. 437 448.

SPINK, Peter. The rights approach to local public management: experiences from Brazil. Rev. adm. empres. [online]. 2000, vol.40, n.3, pp. 45-65.

SUPLICY, Eduardo Matarazzo. 0 direito de participar da riqueza da nação: do Programa Bolsa Família à Renda Básica de Cidadania. Ciênc. saúde coletiva [online]. 2007, vol.12, n.6, pp. 1623-1628.

TAVOLARO, Sergio B. F. and TAVOLARO, Lília G. M.. A cidadania sob o signo do desvio: Para uma crítica da "tese de excepcionalidade brasileira". Soc. estado. [online]. 2010, vol.25, n.2, pp. 331-368.

TAVOLARO, Sergio B. F.. Para além de uma "cidadania à brasileira": uma consideração crítica da produção sociológica nacional. Rev. Sociol. Polit. [online]. 2009, vol.17, n.32, pp. 95-120.

TAVOLARO, Sergio B. F.. Quando discursos e oportunidades políticas se encontram: para repensar a sociologia política da cidadania moderna. Novos estud. - CEBRAP [online]. 2008, n.81, pp. 117-136. 
TENORIO, Fernando. A reforma psiquiátrica brasileira, da década de 1980 aos dias atuais: história e conceitos. Hist. cienc. saude-Manguinhos [online]. 2002, vol.9, n.1, pp. 25-59.

THURLER, Ana Liési. Outros horizontes para a paternidade brasileira no século XXI?. Soc. estado. [online]. 2006, vol.21, n.3, pp. 681-707.

TIEDEMANN, Peter W.. Conteúdos de química em livros didáticos de ciências. Ciênc. educ. (Bauru) [online]. 1998, vol.5, n.2, pp. 15-22.

VALLA, Victor V.. Educação, saúde e cidadania: investigação científica e assessoria popular. Cad. Saúde Pública [online]. 1992, vol.8, n.1, pp. 30-40.

VALLE, Lílian do. Ainda sobre a formação do cidadão: é possível ensinar a ética?. Educ. Soc. [online]. 2001, vol.22, n.76, pp. 175-196.

VALLE, Lílian do. Bases antropológicas da cidadania brasileira: sobre escola pública e cidadania na Primeira República. Rev. Bras. Educ. [online]. 2002, n.19, pp. 29-42.

VAN DER SCHAAF, Alie. Jeito de mulher rural: a busca de direitos sociais e da igualdade de gênero no Rio Grande do Sul. Sociologias [online]. 2003, n.10, pp. 412-442.

VASCONCELOS, Anselmo Ferreira. Societal marketing concept and spirituality in the workplace theory: finding the common ground. Cad. EBAPE.BR [online]. 2011, vol.9, n.1, pp. 96-115.

VENERA, Raquel Alvarenga Sena. Sentidos da educação cidadã no Brasil. Educ. rev. [online]. 2009, n.34, pp. 231-240.

VERGARA, Sylvia Constant and BRANCO, Paulo Durval. Empresa humanizada: a organização necessária e possível. Rev. adm. empres. [online]. 2001, vol.41, n.2, pp. 20-30.

VERRANGIA, Douglas and SILVA, Petronilha Beatriz Gonçalves e. Cidadania, relações étnico-raciais e educação: desafios e potencialidades do ensino de ciências. Educ. Pesqui. [online]. 2010, vol.36, n.3, pp. 705-718.

VIANNA, Luiz Werneck; BURGOS, Marcelo Baumann and SALLES, Paula Martins. Dezessete anos de judicialização da política. Tempo soc. [online]. 2007, vol.19, n.2, pp. 39-85.

VIEIRA, Camila Mugnai and BARROS, Mari Nilza Ferrari de. Cidadania: entre o compromisso e a indiferença: desvendando as representações sociais de universitários. Psicol. estud. [online]. 2008, vol.13, n.3, pp. 513-522.

VIEIRA, EVALDO. A política e as bases do direito educacional. Cad. CEDES [online]. 2001, vol.21, n.55, pp. 9-29. 
XIMENES, Julia Maurmann. 0 supremo tribunal federal e a cidadania à luz da influência comunitarista. Rev. direito GV [online]. 2010, vol.6, n.1, pp. 119-141.

ZALUAR, Alba and LEAL, Maria Cristina. Violência extra e intramuros. Rev. bras. Ci. Soc. [online]. 2001, vol.16, n.45, pp. 145-164.

ZALUAR, Alba. EXCLUSÃO E POLÍTICAS PÚBLICAS: DILEMAS TEÓRICOS E ALTERNATIVAS POLÍTICAS. Rev. bras. Ci. Soc. [online]. 1997, vol.12, n.35.

Recebido em 14.09.2013

Aprovado em 12.11.2013 